\title{
Stress granules are shock absorbers that prevent excessive innate immune responses to dsRNA
}

\author{
Cristhian Cadena ${ }^{1,2,4,7,10}$, Max Paget ${ }^{1,2,4,10}$, Hai-Tao Wang ${ }^{2,4}$, Ehyun Kim ${ }^{4}$, Sadeem Ahmad ${ }^{2,4}$, \\ Qianxia Zhang ${ }^{2,4}$, Beechui Koo ${ }^{5}$, Shawn M. Lyons ${ }^{3,6,8}$, Pavel Ivanov ${ }^{3,6}$, Xin $\mathrm{Mu}^{2,4,9}$ \& Sun \\ $\operatorname{Hur}^{1,2,4 *}$
}

${ }^{1}$ Program in Virology, Division of Medical Sciences

${ }^{2}$ Department of Biological Chemistry and Molecular Pharmacology

${ }^{3}$ Department of Medicine

Harvard Medical School, Boston, MA 02115, USA

${ }^{4}$ Program in Cellular and Molecular Medicine

Boston Children's Hospital, MA 02115, USA

${ }^{5}$ Morrisey School of Arts and Science, Boston College, Chestnut Hill, USA

${ }^{6}$ Division of Rheumatology, Inflammation, and Immunity,

Brigham and Women's Hospital, Boston, MA 02115, USA

${ }^{7}$ Current address: Genentech Inc., CA 94080, USA

${ }^{8}$ Current address: Boston University School of Medicine, MA 02118, USA

${ }^{9}$ Current address: School of Pharmaceutical Science and Technology, Tianjin University, Tianjin 300072, China

${ }^{10}$ These authors contributed equally: Cristhian Cadena, Max Paget

*Correspondence: Sun.Hur@crystal.harvard.edu 


\section{Summary}

Proper defense against microbial infection depends on the controlled activation of the immune system. This is particularly important for the innate immune receptors that recognize viral double-stranded RNA (dsRNA) and initiate antiviral immune responses with the potential of triggering systemic inflammation and immunopathology. How the functions of the dsRNA receptors and their downstream effector molecules are coordinately regulated to avoid excessive immune response is poorly understood. We here demonstrate that stress granules (SGs), biomolecular condensates that form in response to various stresses including viral dsRNA ${ }^{1,2}$, play key roles in regulating dsRNA-triggered immune response. Upon dsRNA stimulation, SGs recruit many innate immune molecules, including RIG-I-like receptors (RLRs), protein kinase R (PKR) and oligoadenylate synthases (OASes), target these molecules and dsRNA for autophagy and limit their functions through sequestration. In the absence of SGs, dsRNA stimulation results in hyperactivation of inflammatory signaling pathways, global translational arrest and bulk RNA degradation, altogether compromising the cellular capacity to restore homeostasis and triggering cell death. In contrast to most dsRNA-induced immune signaling pathways that are hyperactivated in the absence of SGs, a sub-branch of the RLR pathway (IRF3-dependent type I interferon signaling) shows time-dependent changes, where the initial spike in signaling is followed by a significant drop due to increased caspase-dependent negative feedback regulation. This highlights the role of SGs in regulating the delicate balance between the type I interferon pathway and cell death. Altogether, our data suggest that cells utilize SGs as shock absorbers to moderate antiviral innate immune response, thereby allowing cells to guard against its own immune system as well as viruses. 


\section{Main text}

Detection of foreign nucleic acids is central to innate immune defense in all kingdoms of life. dsRNA is one such foreign nucleic acid that triggers innate immune responses in vertebrates. It has long been thought that dsRNAs are produced only during viral infection, where RNA genome is copied to generate viral progeny. However, accumulating evidence suggests that dsRNAs can be produced from many dysregulated cellular processes in the absence of infection, activating the very same inflammatory pathways as in infected cells ${ }^{3,4}$. Accordingly, the innate immune and inflammatory response to dsRNAs underlie diverse pathologies from autoimmunity to neurodegeneration and to metabolic disorders ${ }^{5-7}$.

Three cytosolic dsRNA sensors-RLRs, PKR and OASes-often shape cellular responses to dsRNA in vertebrates ${ }^{3}$. RLRs (RIG-I and MDA5) engagement with dsRNA activates the mitochondrial signaling molecule MAVS, which in turn stimulates several innate immune signaling pathways. One of the best characterized MAVS-dependent downstream responses is the induction of type I interferons (IFN) (e.g. IFN $\beta$ ) mediated by the transcription factor IRF3 (Figure 1a). On the other hand, dsRNA binding to PKR results in suppression of global protein synthesis via auto-phosphorylation of PKR and phosphorylation of the translational initiation factor eIF2 $\alpha$ (Figure 1a). Binding of dsRNA to OASes also results in global translational suppression, but this is mediated by RNase L, a ribonuclease that cleaves the bulk of cytosolic RNAs, including rRNAs, tRNAs and many mRNAs, with limited specificity (Figure 1a). The common downstream consequence of the three pathways is inhibition of viral replication, suppression of cell proliferation and, in extreme cases, cell death.

One consequence of dsRNA-induced PKR activation is the formation of SGs, which is part of broadly conserved cellular responses to diverse stresses including dsRNA ${ }^{1,2}$. As a result of PKRmediated translational arrest, stalled ribosome-mRNA complexes accumulate and aggregate to form SGs. While the exact functions of SGs in translational suppression and cellular stress response is still debated, in the context of innate immunity, SGs have been considered signaling hubs that recruit innate immune molecules, thereby increasing their local concentrations and assisting their multimerization and signaling functions ${ }^{8,9}$. This was considered in line with the 
observation that many viruses suppress or modify SGs, albeit often through indirect and pleiotropic mechanisms ${ }^{10-12}$. We here provide evidence that SGs play a key role in controlling innate immune response to dsRNA, by sequestering innate immune molecules and preventing excessive immune activation and cell death.

\section{SGs recruit the RLR-MAVS signalosomes upon dsRNA stimulation and suppress their antiviral signaling activity.}

We first began by examining the role of SGs in the RLR signaling pathway. We used a model system where cells were stimulated with in vitro transcribed 162 bp dsRNA harboring 5'triphosphate groups (5' ppp), which recapitulates the RIG-I activation process during viral infection $^{13}$. Consistent with previous reports ${ }^{8,9,14}$, we found that dsRNA transfection results in the formation of RLRs and MAVS foci that overlap with SGs, as visualized by the SG markers G3BP1 or TIAR ${ }^{1,2,10}$ (Figure 1b; Extended Data Fig 1a-c). This was observed in all three cell lines examined, U2OS, A549 and HeLa, which are known to have the functional RLR pathway (Extended Data Fig 1a, b). We also found that dsRNAs and downstream signaling molecules, such as TBK1 and TRAF2/6, colocalized with SGs (Extended Data Fig 1c). SG localization of RLRs and MAVS was impaired in G3BP1/2 double knockout ( $\triangle \mathrm{G} 3 \mathrm{BPs}$ ) cells (Figure $1 \mathrm{~b}$ ), suggesting that these granules are canonical SGs that utilize G3BPs as nucleators ${ }^{1,2,10}$.

We next compared RLR signaling in WT and SG-deficient $\triangle$ G3BPs U2OS cells by measuring the expression levels of IFN $\beta, I L-6$ and RANTES, genes known to be induced by RLR signaling. We used two time points, 6 and $24 \mathrm{hr}$ post-dsRNA transfection, to examine the effect of SGs at both early and late stages of RLR signaling. At $6 \mathrm{hr}$, all three genes were efficiently induced upon dsRNA stimulation in both WT and $\triangle \mathrm{G} 3 \mathrm{BPs}$ cells, but they were more significantly induced in $\triangle \mathrm{G} 3 \mathrm{BP}$ s cells than in WT cells (Figure 1c). At $24 \mathrm{hr}$, however, different genes displayed different trends. In both WT and $\triangle \mathrm{G} 3 \mathrm{BP}$ s cells, the RANTES levels did not drastically change from 6 to $24 \mathrm{hr}$, maintaining the higher level in $\triangle \mathrm{G} 3 \mathrm{BP}$ s than in WT cells. In contrast, the IFN $\beta$ level in $\triangle \mathrm{G} 3 B$ Ps dropped sharply from 6 to $24 \mathrm{hr}$, resulting in a slightly lower level in $\triangle \mathrm{G} 3 \mathrm{BP}$ s than in WT cells. Intriguingly, we also noticed a more pronounced cell death in 
$\triangle$ G3BPs than in WT cells at $24 \mathrm{hr}$ (to be discussed in Figure 3), raising the possibility that latestage signaling events may be interfered by concurrent cell death.

To further examine the transcriptional response at the genome-wide level, we performed RNAseq analysis with WT and $\triangle \mathrm{G} 3 \mathrm{BP}$ s U2OS cells. The result showed that the hyperinduction in $\triangle \mathrm{G} 3 \mathrm{BPs}$ at $6 \mathrm{hr}$ is globally seen for most genes induced by dsRNA (Figure 1d; Extended Data Fig 2a). There were a small number of outlier genes, but their induction was largely independent of MAVS (Extended Data Fig 2b), supporting the idea that RLR-MAVS signaling is enhanced in the absence of SGs. We also noticed that, while most genes increased in expression in $\triangle G 3 B P s$ from 6 to $24 \mathrm{hr}$ post-dsRNA (similar to RANTES in Figure 1c), a subset of genes decreased from $6 \mathrm{hr}$ to $24 \mathrm{hr}$ (similar to $I F N \beta$ in Figure 1c) (Extended Data Fig 2c). Similar to the trend of the $I F N \beta$ gene induction, the level of IRF3 activation, as measured by p-IRF3 (Figure 1e) or nuclear IRF3 translocation (Figure 1f), was higher in $\triangle$ G3BPs at $6 \mathrm{hr}$ post-dsRNA stimulation, before they decreased at 16-24 hr time points. Altogether, these results revealed that $\triangle \mathrm{G} 3 \mathrm{BP}$ s cells activate antiviral signaling pathways more efficiently than WT cells at early time points. In contrast, at later time points, the signaling pattern shows more complex behavior in $\Delta \mathrm{G} 3 \mathrm{BPs}$ cells.

We next examined whether the early hypersignaling in $\triangle \mathrm{G} 3 \mathrm{BP}$ s is limited to the U2OS cell line or the choice of model dsRNA. We found that A549 and HeLa cells also displayed hypersignaling in $\triangle \mathrm{G} 3 \mathrm{BPs}$ than in WT cells at $4 \mathrm{hr}$ post-dsRNA (Extended Data Fig 3a-b). Note that an earlier time point was used as these cells respond to dsRNA more rapidly than in U2OS cells. Similarly, RLR signaling upon $\mathrm{SeV}$ and EMCV infection was more robust in $\triangle \mathrm{G} 3 \mathrm{BP}$ s than in WT U2OS cells (Extended Data Fig 3c-d). However, antiviral signaling in response to cGAMP, which activates the cGAS-STING pathway without triggering the formation of SGs, was comparable in WT and $\Delta \mathrm{G} 3 \mathrm{BP}$ s cells (Extended Data Fig 3e). These results suggest G3BPs, and therefore SGs, suppress RLR signaling in multiple cell lines, but this is not due to a general decrease in antiviral signaling efficiency.

To further confirm that the hypersignaling observed in $\triangle \mathrm{G} 3 \mathrm{BP}$ s cells is indeed due to the absence of SGs, rather than potential SG-independent functions of G3BPs, we examined RLR 
signaling in U2OS cells lacking PKR, which is required to form SGs upon dsRNA stimulation ${ }^{1,2}$ (Figure 1a). A previous study suggested that in the absence of PKR, dsRNA stimulation leads to formation of foci distinct from SGs in their compositions and granule shapes ${ }^{15}$. In line with this report, we found that $\triangle \mathrm{PKR}$ cells still form G3BP1 foci upon dsRNA stimulation, which contained RIG-I but lacked MAVS and TIAR, and were smaller in size (Extended Data Fig 4a). The signaling behavior of $\triangle \mathrm{PKR}$ cells was also distinct from WT at both 6 and $24 \mathrm{hr}$ (Extended Data Fig $4 b-c)$, largely mirroring the pattern of $\Delta$ G3BPs cells. This result suggests that the granules in $\triangle \mathrm{PKR}$ cells do not exert the same suppressive effect as SGs induced by PKR. Together, these results show that SGs negatively regulate RLR signaling in response to dsRNA stimulation.

\section{dsRNA-induced SGs are targeted by autophagy, which together suppress RLR signaling.}

We next asked how SGs suppress RLR signaling. Previous studies suggested that prolonged exposure to cellular stress can lead to autophagic degradation of $\mathrm{SGs}^{16}$, while transient exposure allows for the spontaneous dissolution of SGs independent of autophagy ${ }^{2,17}$. By virtue of being a membrane-impermeable macromolecule, dsRNA stimulus is inherently long-lasting once introduced inside the cell. Thus, we asked whether dsRNA-induced SGs are targeted by autophagy, and thereby suppress RLR signaling. To test this hypothesis, we first examined the localization of LC3B, a ubiquitin-like protein that plays an important role in autophagy and a common marker for autophagophores. In all three cell lines examined (U2OS, A549 and HeLa), we found that LC3B colocalized with SGs (Figure 2a; Extended Data Fig 5a). SG localization of LC3B was also observed in cells stimulated with dsRNA through electroporation, or cells infected with Sendai virus (SeV) and encephalomyocarditis virus (EMCV) (Extended Data Fig 5b). LC3B colocalization was impaired in autophagy-deficient $\triangle \mathrm{ATG} 7$ cells (Figure 2a; Extended Data Fig 5c) or in the presence of autophagy inhibitor SAR405 (Extended Data Fig 5d), suggesting that LC3B recruitment is mediated by autophagy. No LC3B foci were observed in $\triangle \mathrm{G} 3 \mathrm{BP}$ s cells (Figure 2a; Extended Data Fig 5a), suggesting that LC3B recruitment occurs post-SG formation. LC3B recruitment appears to occur rapidly, as we did not find SGs that do not contain LC3B at any time point (as early as $2 \mathrm{hr}$ post-dsRNA transfection when SGs become visible) (Extended Data Fig 5e). It is also noteworthy that the LC3B/SG foci remain visible as 
late as $24 \mathrm{hr}$ post-dsRNA (Extended Data Fig 5e), suggesting that new SGs continuously form and undergo autophagy over $24 \mathrm{hr}$ or autophagic degradation of the SG contents is slow.

We next examined whether autophagy of dsRNA-induced SGs in fact leads to the formation of autolysosomes, the final step of autophagy and the product of autophagosome-lysosome fusion. SGs induced by dsRNA colocalized with lysosomal proteins, such as cathepsin D and LAMP2, while their colocalization was blocked by Bafilomycin A1 (BafA), an inhibitor of autophagosome-lysosome fusion (Extended Data Fig 6). Autolysosomal fate of SGs was also evident when RIG-I was traced using a Keima fusion protein, a fluorescent reporter that changes the excitation spectrum from $440 \mathrm{~nm}$ in a neutral environment to $586 \mathrm{~nm}$ in an acidic environment ${ }^{18}$. Upon dsRNA transfection, Keima-RIG-I changed its fluorescent spectrum indicating the acidification of its environment (Figure 2b). This change was absent in the presence of BafA (Figure 2b). Together, these results suggest that SGs with RLRs are indeed targeted by autophagy and incorporated into autolysosomes.

We next asked whether autophagy contributes to SG-mediated suppression of RLR signaling. WT and autophagy-deficient $\triangle \mathrm{ATG} 7$ cells displayed similar signaling activities at $6 \mathrm{hr}$ postdsRNA. However, at $24 \mathrm{hr}$, higher levels of IFN $\beta$ mRNA and phosphorylated IRF3 were observed in $\triangle \mathrm{ATG} 7$ cells (Figures $2 \mathrm{c}-\mathrm{d}$ ). These results suggest that while autophagy provides a mechanism for tightly suppressing RLR signaling over $\sim 24 \mathrm{hr}$, SGs are sufficient for the suppression during the early stage of the RLR response.

In order to more directly examine the effect of SGs and autophagy on the activity of the RLRMAVS signalosome, we used cell-free assays and measured the signaling potential of MAVS isolated from cells ${ }^{19}$. Since MAVS is anchored to the outer mitochondrial membrane and is directed to SGs upon dsRNA stimulation, we isolated mitochondria and SGs by centrifugation (P18 in Figure 2e) from WT, $\triangle$ G3BPs and $\triangle \mathrm{ATG} 7 \mathrm{U} 2 \mathrm{OS}$ cells $6 \mathrm{hr}$ post-dsRNA stimulation or mock treatment. An equivalent amount of P18 was then mixed with in vitro-translated ${ }^{35} \mathrm{~S}-$ labeled IRF3 and the cytosolic fraction (S18) from unstimulated WT cells, which provides a pool of downstream signaling molecules in the resting state. Because pre-activated MAVS from different cells are mixed with a common source of quiescent downstream signaling molecules, 
this assay allows a direct comparison of the signaling potential of the MAVS from different cellular sources. The effect of MAVS on the cytosolic signaling molecules was measured by monitoring the transition of ${ }^{35} \mathrm{~S}-\mathrm{IRF} 3$ from the inactive monomeric state to the active dimeric state by native gel analysis. Consistent with the cellular signaling assays, P18 from WT cells (i.e. with SGs) was significantly less efficient in activating IRF3 than those from $\Delta$ G3BPs cells (i.e. without SGs). This signaling activity is entirely dependent on MAVS as P18 from $\triangle$ G3BPs $\triangle$ MAVS cells did not stimulate IRF3 dimerization (Figure 2f). Furthermore, the IRF3stimulatory activity of P18 from $\triangle \mathrm{ATG} 7$ cells was similar to that of WT cells, but significantly lower than that of $\triangle \mathrm{G} 3 \mathrm{BPs}$ cells. These results collectively suggest that SGs alone can negatively impact RLR signaling independent of autophagy, presumably by sequestering RLRs, MAVS and their signalosomes within the dense condensate structure and preventing them from activating the downstream pathway.

\section{SGs dampen dsRNA-triggered apoptosis and the consequent negative feedback regulation of IRF3}

We were intrigued by the significant drop in the level of IRF3 activity at $24 \mathrm{hr}$ following their hyperinduction at $6 \mathrm{hr}$ post-dsRNA (Figure 1). As mentioned earlier, we noticed marked increase in cell death in $\triangle \mathrm{G} 3 \mathrm{BP}$ s cells upon dsRNA stimulation, as measured by the loss of cell attachment to the surface, Sytox uptake, caspase-3/7 activity assay and LIVE/DEAD dye staining (Figure 3a-c; Extended Data Fig 7a). This dsRNA-triggered cell death in $\triangle$ G3BP U2OS occurred with all doses of dsRNA tested (Figure 3c) and progressed gradually over a $24 \mathrm{hr}$ timecourse (Figure $3 b$ ). The dependence on G3BP1/2 is specific to cell death trigger, as other stimuli, such as etoposide and staurosporine, triggered greater cell death in WT than in $\triangle \mathrm{G} 3 \mathrm{BP}$ s cells (Extended Data Fig 7b). Similar increase in dsRNA-triggered cell death was observed with $\triangle$ G3BPs in A549 and HeLa cells (Extended Data Fig 7c-h).

We next characterized dsRNA-induced cell death in U2OS $\Delta$ G3BPs cells. We found that dsRNA stimulation caused PARP cleavage, apoptotic blebs and other morphological changes similar to apoptotic cells, but distinct from those observed with necroptotic or pyroptotic cells (Extended Data Fig 8a, b). Along with PARP cleavage, we found that dsRNA stimulation in $\triangle \mathrm{G} 3 \mathrm{BP}$ 
induced cleavage of multiple caspases, including caspase-3, -8, -9 (Figure 3d), while caspase-1 was not cleaved (Extended Data Fig 8c). Consistent with the notion that $\Delta \mathrm{G} 3 \mathrm{BP}$ s cells undergo apoptosis, a pan-caspase inhibitor (Q-VD-Oph) completely blocked dsRNA-dependent cell death and cleavage of PARP in $\triangle \mathrm{G} 3 \mathrm{BP}$ (Figure 3e-f), but a pyroptosis inhibitor (disulfiram) did not (Extended Data Fig 8d). Thus, dsRNA-mediated cell death in $\triangle$ G3BPs is caspase-dependent apoptosis.

Previous studies suggested that caspase- 8 is activated directly by the RIG-I-MAVS signalosome to suppress IRF3 signaling ${ }^{20,21}$. This led us to test whether caspase- 8 is the upstream trigger for other caspases in $\triangle \mathrm{G} 3 \mathrm{BP}$ s cells. We found that treatment with a caspase-8 inhibitor (Z-IETDFMK) or CRISPR-knockout of caspase-8 impaired cleavage of caspases-3 and 9, upon dsRNA stimulation (Extended Data Fig 8e). However, Z-IETD-FMK did not prevent dsRNA-induced cell death. Instead of apoptosis, inhibition of caspase- 8 in $\triangle$ G3BPs cells resulted in necroptosis involving RIPK1 phosphorylation (Extended Data Fig 8f). These results suggest that caspase-8 plays a key role in dsRNA-triggered apoptosis in $\triangle$ G3BPs U2OS cells, but cell death can be rerouted when caspase- 8 is blocked ${ }^{22}$.

To examine whether cell death or caspase activities are responsible for the marked decline in the IRF3 activity from $6 \mathrm{hr}$ to $24 \mathrm{hr}$ post-dsRNA, we examined the impact of Q-VD-Oph on IRF3 phosphorylation. Treatment with Q-VD-Oph did not affect SG formation in WT cells (Extended Data Fig 8g). It also did not affect the p-IRF3 level in WT or $\Delta \mathrm{G} 3 B P$ s cells at $6 \mathrm{hr}$ post-dsRNA (Figure 3g). However, the level of p-IRF3 at $24 \mathrm{hr}$ in $\triangle \mathrm{G} 3 \mathrm{BPs}$, but not WT cells, was largely rescued by Q-VD-Oph (Figure 3g), suggesting that the activity of the caspase pathways or induction of cell death itself was the cause for the large reduction in IRF3 signaling. Similar effect of Q-VD-Oph was observed on the level of IFN $\beta$ induction in U2OS $\triangle$ G3BPs (Figure $3 \mathrm{~h}$ ) or A549 $\Delta$ G3BPs cells (Extended Data Fig 8h). Collectively, these results suggest that SGs prevent dsRNA-induced caspase activation and cell death, which allows cells to bypass caspasedependent negative feedback regulation of RLR-MAVS-IRF signaling at later stages.

\section{SGs suppress a broad range of innate immune pathways and prevent overstimulation by dsRNA and consequent cell death}


We next investigated upstream events that trigger cell death in $\triangle \mathrm{G} 3 \mathrm{BP}$ s cells in response to dsRNA. Previous studies suggested that MAVS can induce cell death through both IFNdependent and -independent manners ${ }^{21,23,24}$. Thus, we first examined whether hyperactivation of the RLR signaling pathway is responsible for the increased cell death in $\Delta$ G3BPs cells. Knocking out MAVS largely rescued cell viability in U2OS $\triangle$ G3BPs upon dsRNA stimulation, while knocking out IRF3 did not (Figure 4a). This is despite the fact that IFN $\beta$ induction in U2OS $\triangle$ G3BPs was nearly completely dependent on both MAVS and IRF3 (Extended Data Fig 9a). In addition, inhibitors of TBK1 and JAK that respectively block IRF3 activation and the downstream actions of type I IFNs did not alleviate dsRNA-triggered cell death in $\triangle \mathrm{G} 3 \mathrm{BPs}$ (Extended Data Fig 9b). These results suggest that the cell death in $\triangle$ G3BPs is mediated by a MAVS-dependent, but IFN-independent mechanism. Consistent with the role of MAVS in dsRNA-induced cell death in $\triangle$ G3BPs cells, $\triangle$ MAVS also significantly reduced cleavage of caspases-3, -8 and -9, albeit not to completion (Extended Data Fig 9c). Similar $\triangle$ MAVSdependent rescue of cell viability and caspase-3/7 activity was observed with A549 $\Delta$ G3BPs (Extended Data Figure 9d). These results suggest that cell death-inducing activity of MAVS, along with its ability to induce IFNs, is amplified in the absence of SGs.

To understand the mechanism by which MAVS triggers cell death, we examined genes involved in apoptosis by RNA-seq/KEGG pathway analysis (Extended Data Fig 9e). The result showed that, upon dsRNA stimulation, genes involved in cell death or apoptosis are hyperinduced in $\triangle$ G3BPs than in WT cells. Interestingly, many of these genes, including TNF (TNF $\alpha$ ), FAS and TNFRSF10B (DR5), are dependent on MAVS, but not on IRF3. Furthermore, blocking TNF $\alpha$ signaling using anti-TNF $\alpha$ markedly reduced cell death in $\triangle \mathrm{G} 3 \mathrm{BPs}$ upon dsRNA stimulation (Extended Data Fig 9f). However, treatment with TNF $\alpha$ alone in $\triangle$ G3BPs does not induce cell death (Extended Data Fig 9g), suggesting that the collective actions of multiple apoptotic genes induced by MAVS account for dsRNA-triggered cell death in $\triangle \mathrm{G} 3 B \mathrm{BP}$.

Given that knocking out MAVS does not completely relieve dsRNA toxicity in $\triangle \mathrm{G} 3 \mathrm{BPs}$ cells, we next examined whether other dsRNA sensing molecules, such as PKR and the OASes-RNase L system, are also contributing factors (Figure 1a). In fact, PKR, OAS3 and RNase L also 
localized at SGs upon dsRNA stimulation (Extended Data Fig 10a ${ }^{25,26}$, raising the question of whether SGs also regulate their activities as with MAVS. Consistent with this notion, the PKR activity was more potently induced by dsRNA in $\triangle \mathrm{G} 3 B P$ s than in WT cells, as measured by the level of p-PKR and ATF4, a gene known to be induced upon PKR activation (Figure 4b). Similarly, RNase L was significantly more active in $\triangle \mathrm{G} 3 \mathrm{BP}$ s than in WT cells, as measured by rRNA cleavage that can be visualized through electrophoresis of total RNAs (Figure 4c). Remarkably, nearly all rRNAs were degraded in $\triangle \mathrm{G} 3 B$ Ps cells upon dsRNA stimulation, which depends entirely on RNase L, but largely independent of MAVS. Consistent with the role of PKR and OASes-RNaseL in cell death, knocking out PKR and RNase L partially relieved dsRNA-triggered cell death in U2OS $\Delta$ G3BPs cells, albeit not to the same extent as MAVS deletion (Figure 4d, e). In A549 $\Delta$ G3BPs cells, knocking out RNase L led to a significant relief of cell death, but knocking out PKR had little impact, suggesting that the contribution of each dsRNA-sensing pathway can vary depending on cell type (Extended Data Fig 10b, c).

Altogether, our data indicate that SGs regulate diverse dsRNA receptors and innate immune signaling molecules, sequestering them within SGs and autophagosomes and preventing their excessive response to foreign dsRNA, including cell death.

\section{Discussion}

Phase separation has recently emerged as a widespread phenomenon that occurs in many biological processes, from transcription to signal transduction ${ }^{27,28}$. Functions of phase separation, however, remain unclear in most cases. We here demonstrate that SGs exert a negative impact on a broad range of dsRNA sensors and effectors upon dsRNA stimulation, likely by sequestering them within SGs and preventing their downstream activities in the cytosol (Figure 4f). While dsRNA-induced SGs are targeted by autophagy, which provides an additional mechanism to further limit cytosolic access to SG-localized signaling molecules, SG formation alone is largely sufficient to suppress RLR signaling. This may reflect the fact that MAVS signaling requires a continuous exchange of downstream signaling molecules (e.g. IRF3) with the cytoplasm, which is likely limited within the dense SG structure. In the absence of SGs, all three branches of dsRNA sensing pathways (RLR, PKR and OASes-RNase L, Figure 1a) are hyperactivated, leading to excessive innate immune response and cell death (Figure 4f). Interestingly, a sub- 
branch of the RLR pathways (e.g. IRF3) showed a spike followed by a strong suppression due to the negative feedback regulation by apoptotic caspases. This highlights the role of SGs in regulating the delicate balance between the type I interferon pathway and cell death ${ }^{29}$. Altogether, our results suggest that dsRNA-induced SG functions as a "shock absorber" to enable the controlled activation of a broad range of dsRNA-dependent innate immune pathways, increasing the temporal window for mounting an appropriate immune response while maintaining its magnitude below the "death" threshold (Figure 4f).

Our findings raise a question why certain viruses inhibit SGs despite its role in regulating immune response and cell death. We speculate that this is because dsRNA-induced SGs have a global sequestration effect that extends beyond innate immune molecules, but into viral dsRNAs (as we demonstrated here, Extended Data Fig 1c), and other host and viral factors necessary for viral replication (as reported in previous studies ${ }^{10-12}$ ). For example, all viruses utilize the host ribosome to synthesize viral proteins, but the $40 \mathrm{~S}$ subunit is sequestered within $\mathrm{SGs}^{10,11}$, which would limit the translational resource for viruses. Our observations thus highlight the multifunctional nature of SGs that cannot be simply categorized into anti- or pro-viral activities. Rather, the diverse functions of dsRNA-triggered SGs may be best captured with the analogy to a global waste sink that sequesters viral dsRNAs, innate immune molecules and other cellular and viral components, thereby protecting cells from toxic immune response as well as viruses. This is in line with the observation that different viruses cope with SGs differently; some inhibit SGs, while others alter or take advantage of SGs ${ }^{10-12}$. Thus, our study provides a new foundation to investigate host-virus interactions, dsRNA biology and innate immune regulation, with the potential of guiding new avenues for antiviral or immune-modulatory therapies.

Acknowledgement: We acknowledge Drs. Paul Anderson, Wade Harper, Igor Brodsky and the rest of the Hur lab members for helpful discussions. We thank Dr. Takashi Fujita for sharing anti-IRF3 antibody. Part of cell images were collected at the Nikon imaging center at Harvard Medical School. This work was supported by NSF fellowship (CC), Roche post-doctoral fellowship (HW), and NIH grants to SML (R00GM124458), PI (R01GM126150) and SH (R01AI154653, R01AI111784 and DP1AI152074). 


\section{References}

1 Protter, D. S. W. \& Parker, R. Principles and Properties of Stress Granules. Trends Cell Biol 26, 668-679, doi:10.1016/j.tcb.2016.05.004 (2016).

2 Hofmann, S., Kedersha, N., Anderson, P. \& Ivanov, P. Molecular mechanisms of stress granule assembly and disassembly. Biochim Biophys Acta Mol Cell Res 1868, 118876, doi:10.1016/j.bbamcr.2020.118876 (2021).

3 Hur, S. Double-Stranded RNA Sensors and Modulators in Innate Immunity. Annu Rev Immunol 37, 349-375, doi:10.1146/annurev-immunol-042718-041356 (2019).

4 Kim, S., Ku, Y., Ku, J. \& Kim, Y. Evidence of Aberrant Immune Response by Endogenous Double-Stranded RNAs: Attack from Within. Bioessays 41, e1900023, doi:10.1002/bies.201900023 (2019).

5 Uggenti, C., Lepelley, A. \& Crow, Y. J. Self-Awareness: Nucleic Acid-Driven Inflammation and the Type I Interferonopathies. Annu Rev Immunol 37, 247-267, doi:10.1146/annurev-immunol-042718-041257 (2019).

6 Saldi, T. K., Gonzales, P. K., LaRocca, T. J. \& Link, C. D. Neurodegeneration, Heterochromatin, and Double-Stranded RNA. J Exp Neurosci 13, 1179069519830697 , doi:10.1177/1179069519830697 (2019).

7 Sud, N., Rutledge, A. C., Pan, K. \& Su, Q. Activation of the dsRNA-Activated Protein Kinase PKR in Mitochondrial Dysfunction and Inflammatory Stress in Metabolic Syndrome. Curr Pharm Des 22, 2697-2703, doi:10.2174/1381612822666160202141845 (2016).

8 Onomoto, K. et al. Critical role of an antiviral stress granule containing RIG-I and PKR in viral detection and innate immunity. PLoS One 7, e43031 (2013).

9 Oh, S. W. et al. Leader-Containing Uncapped Viral Transcript Activates RIG-I in Antiviral Stress Granules. PLoS Pathog 12, e1005444, doi:10.1371/journal.ppat.1005444 (2016).

10 McCormick, C. \& Khaperskyy, D. A. Translation inhibition and stress granules in the antiviral immune response. Nat Rev Immunol 17, 647-660, doi:10.1038/nri.2017.63 (2017). 
11 White, J. P. \& Lloyd, R. E. Regulation of stress granules in virus systems. Trends Microbiol 20, 175-183, doi:10.1016/j.tim.2012.02.001 (2012).

12 Feng, Q., Langereis, M. A. \& van Kuppeveld, F. J. Induction and suppression of innate antiviral responses by picornaviruses. Cytokine Growth Factor Rev 25, 577-585, doi:10.1016/j.cytogfr.2014.07.003 (2014).

13 Cadena, C. et al. Ubiquitin-Dependent and -Independent Roles of E3 Ligase RIPLET in Innate Immunity. Cell 8, 496-509, doi:10.1016/j.cell.2019.03.017 (2019).

14 Langereis, M. A., Feng, Q. \& van Kuppeveld, F. J. MDA5 localizes to stress granules, but this localization is not required for the induction of type I interferon. J. Virol. 87, 6314-6325 (2013).

15 Burke, J. M., Lester, E. T., Tauber, D. \& Parker, R. RNase L promotes the formation of unique ribonucleoprotein granules distinct from stress granules. J Biol Chem 295, 14261438, doi:10.1074/jbc.RA119.011638 (2020).

16 Buchan, J. R., Kolaitis, R. M., Taylor, J. P. \& Parker, R. Eukaryotic stress granules are cleared by autophagy and Cdc48/VCP function. Cell 153, 1461-1474, doi:10.1016/j.cell.2013.05.037 (2013).

17 Wheeler, J. R., Matheny, T., Jain, S., Abrisch, R. \& Parker, R. Distinct stages in stress granule assembly and disassembly. Elife 5, doi:10.7554/eLife.18413 (2016).

18 Katayama, H., Kogure, T., Mizushima, N., Yoshimori, T. \& Miyawaki, A. A sensitive and quantitative technique for detecting autophagic events based on lysosomal delivery. Chem Biol 18, 1042-1052, doi:10.1016/j.chembiol.2011.05.013 (2011).

19 Hou, F. et al. MAVS forms functional prion-like aggregates to activate and propagate antiviral innate immune response. Cell 146, 448-461, doi:10.1016/j.cell.2011.06.041 (2011).

20 Rajput, A. et al. RIG-I RNA helicase activation of IRF3 transcription factor is negatively regulated by caspase-8-mediated cleavage of the RIP1 protein. Immunity 34, 340-351, doi:10.1016/j.immuni.2010.12.018 (2011).

21 El Maadidi, S. et al. A novel mitochondrial MAVS/Caspase-8 platform links RNA virusinduced innate antiviral signaling to Bax/Bak-independent apoptosis. J Immunol 192, 1171-1183, doi:10.4049/jimmunol.1300842 (2014). 
22 Tummers, B. \& Green, D. R. Caspase-8: regulating life and death. Immunol Rev 277, 7689, doi:10.1111/imr.12541 (2017).

23 Lei, Y. et al. MAVS-mediated apoptosis and its inhibition by viral proteins. PLoS One 4, e5466, doi:10.1371/journal.pone.0005466 (2009).

24 Besch, R. et al. Proapoptotic signaling induced by RIG-I and MDA-5 results in type I interferon-independent apoptosis in human melanoma cells. J Clin Invest 119, 23992411, doi:10.1172/JCI37155 (2009).

25 Reineke, L. C. \& Lloyd, R. E. The stress granule protein G3BP1 recruits protein kinase R to promote multiple innate immune antiviral responses. J Virol 89, 2575-2589, doi:10.1128/JVI.02791-14 (2015).

26 Onomoto, K. et al. Critical role of an antiviral stress granule containing RIG-I and PKR in viral detection and innate immunity. PLoS One 7, e43031, doi:10.1371/journal.pone.0043031 (2012).

27 Alberti, S. \& Hyman, A. A. Biomolecular condensates at the nexus of cellular stress, protein aggregation disease and ageing. Nat Rev Mol Cell Biol 22, 196-213, doi:10.1038/s41580-020-00326-6 (2021).

28 Hnisz, D., Shrinivas, K., Young, R. A., Chakraborty, A. K. \& Sharp, P. A. A Phase Separation Model for Transcriptional Control. Cell 169, 13-23, doi:10.1016/j.cell.2017.02.007 (2017).

29 Ning, X. et al. Apoptotic Caspases Suppress Type I Interferon Production via the Cleavage of cGAS, MAVS, and IRF3. Mol Cell 74, 19-31 e17, doi:10.1016/j.molcel.2019.02.013 (2019). 


\section{Figure arrangement}

SGs recruit the RLR-MAVS signalosomes upon dsRNA stimulation and suppress their antiviral signaling activity.

Figure 1

Extended Data (ED) Fig 1-4

dsRNA-induced SGs are targeted by autophagy, which together suppress RLR signaling. Figure 2

Extended Data (ED) Fig 5-6

SGs dampen dsRNA-triggered apoptosis and the consequent negative feedback regulation of IRF.

Figure 3

Extended Data (ED) Fig 7-8

SGs suppress a broad range of innate immune pathways and prevent overstimulation by dsRNA and consequent cell death.

Figure 4

Extended Data (ED) Fig 9-10 

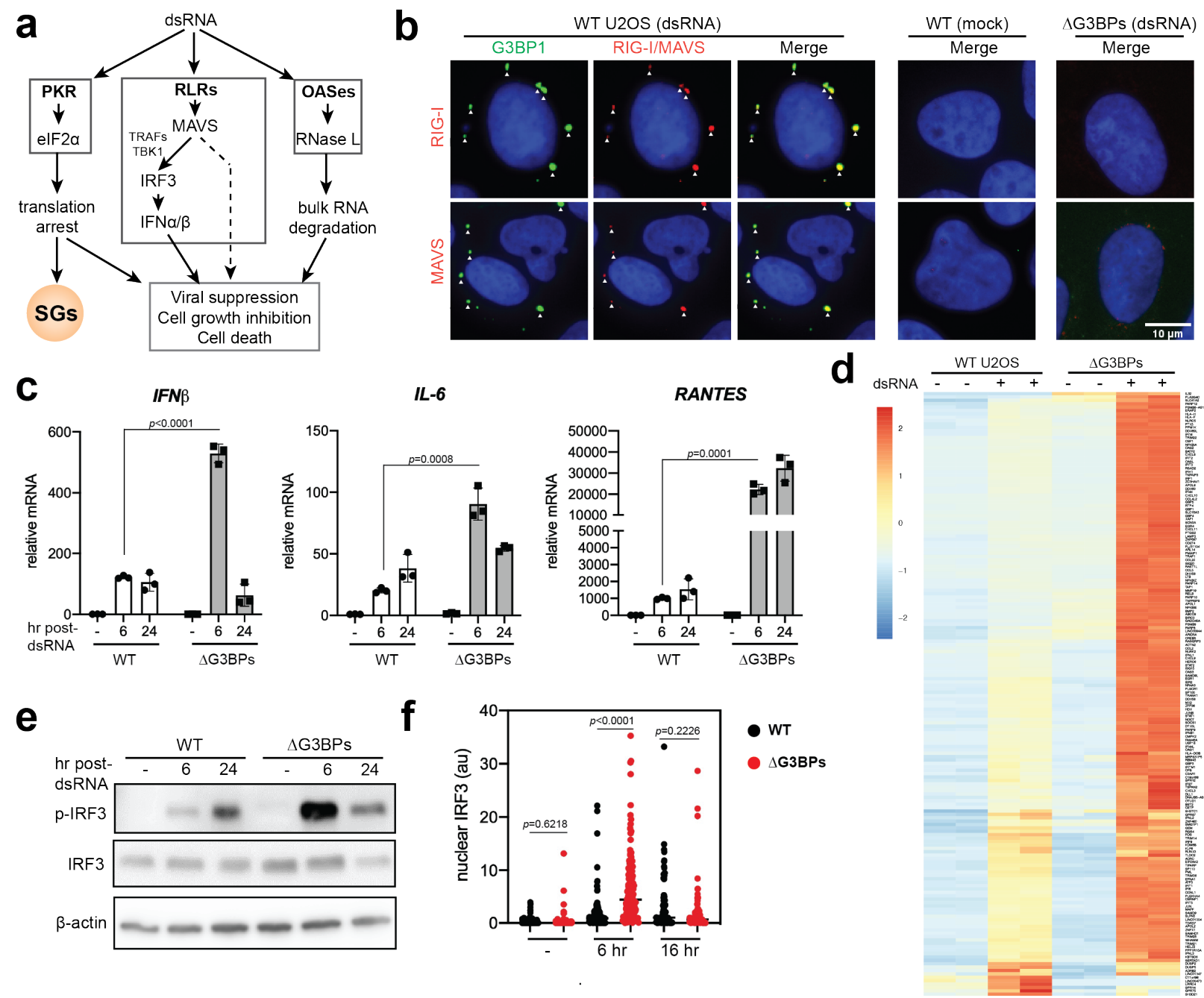

Figure 1. SGs recruit the RLR-MAVS signalosomes upon dsRNA stimulation and suppress their antiviral signaling activity.

a. Schematic of the dsRNA-dependent innate immune pathways discussed in this study. Cytosolic dsRNA activates PKR, RLRs and OASes, which together leads to viral suppression, cell growth inhibition and, in extreme cases, cell death. Activation of PKR also induces SG formation. This study examines the role of SGs on the upstream PKR pathway and the parallel pathways involving RLRs and OASes.

b. Colocalization of RIG-I and MAVS with G3BP1 (green) in U2OS cells (WT vs SGdeficient $\triangle \mathrm{G} 3 \mathrm{BPs}$ ) as analyzed by immunofluorescence. Arrows indicate examples of SGs. See Extended Data Fig 1b for antibody validation. Cells were stimulated with 162 bp dsRNA containing 5'ppp (500 ng/ml) for $6 \mathrm{hr}$ prior to imaging. Manders overlap coefficient is 0.88 for RIG-I and G3BP1, and 0.85 for MAVS and G3BP1. Nuclei of cells were stained with Hoechst 3342.

c. Antiviral signaling in U2OS cells (WT vs $\triangle \mathrm{G} 3 \mathrm{BPs}$ ), as measured by the levels of $I F N \beta$ (left),IL-6 (middle), and RANTES (right) mRNAs. Cells were stimulated with $162 \mathrm{bp}$ dsRNA with 5 'ppp $(500 \mathrm{ng} / \mathrm{ml})$ for 6 or $24 \mathrm{hr}$.

d. Heatmap of z-scores displaying differentially expressed genes in U2OS (WT vs $\Delta$ G3BPs) $6 \mathrm{hr}$ post-dsRNA. Genes showing $\log 2$-fold change $($ lfc 2$)>2$ (with $p \_$adj $\left.<0.05\right)$ upon 
dsRNA stimulation in a MAVS-dependent manner were shown. See Extended Data Fig $2 \mathrm{~b}$ for all genes induced by dsRNAs (1fc2 $>2$ ), and for comparison between $\triangle$ G3BPs and $\triangle \mathrm{G} 3 \mathrm{BP} \triangle \mathrm{MAVS}$ cells. Raw data for the heatmap can be found in the supplemental file (data 1).

e. IRF3 phosphorylation in U2OS cells (WT vs $\triangle \mathrm{G} 3 \mathrm{BPs}$ ) determined by WB. Cells were stimulated as in (c).

f. Nuclear translocation of IRF3 in U2OS cells (WT vs $\triangle$ G3BPs). Cells were stimulated as in (c) and were subjected to immunofluorescence analysis using anti-IRF3 at indicated timepoints. Each data point represents the intensity of nuclear IRF3 signal in each cell (a.u) (n=61-179). DAPI staining was used for defining nuclear boundary. Of note, the latest time-point for this experiment was $16 \mathrm{hr}$, rather than $24 \mathrm{hr}$ to avoid pronounced cell detachment due to cell death (see in Figure 3).

Data in (c) are presented in means $\pm \operatorname{SD}(n=3)$. All data are representative of at least three independent experiments. $p$ values were calculated using the two-tailed unpaired Student's test. 
a
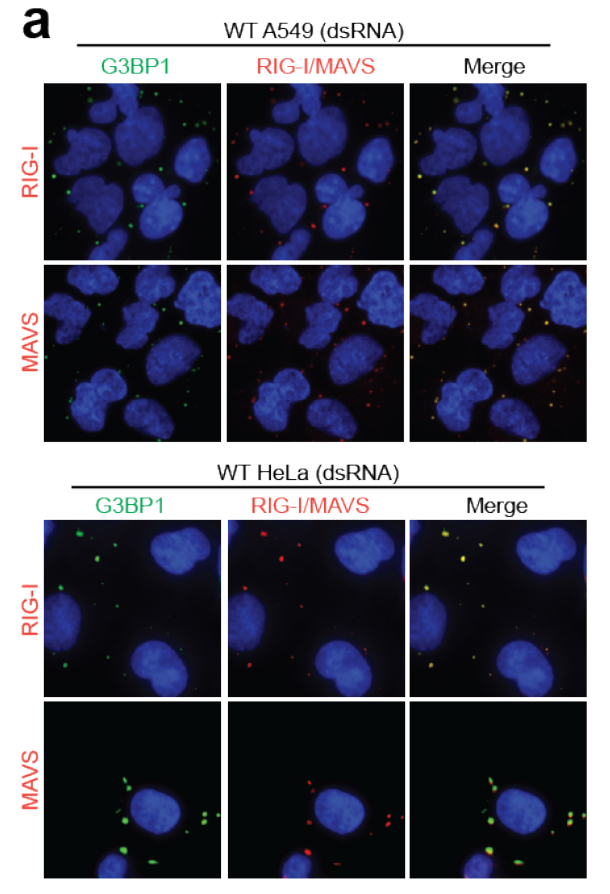

b
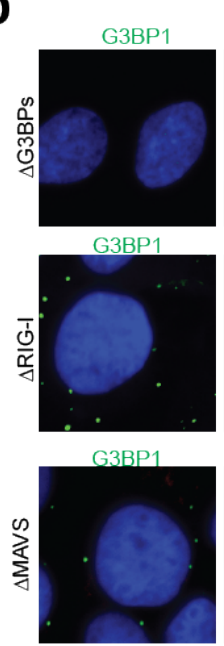
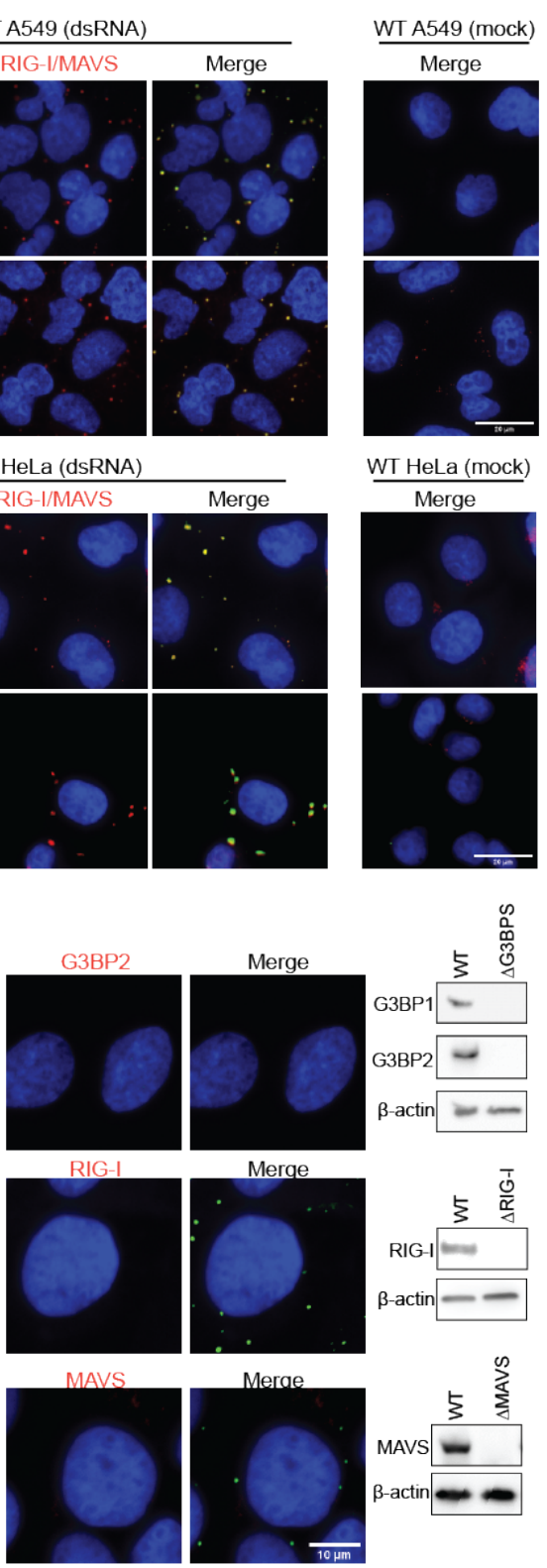

Merge
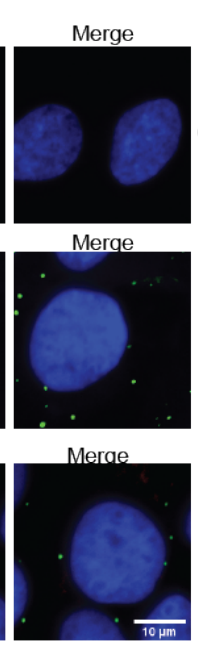

C
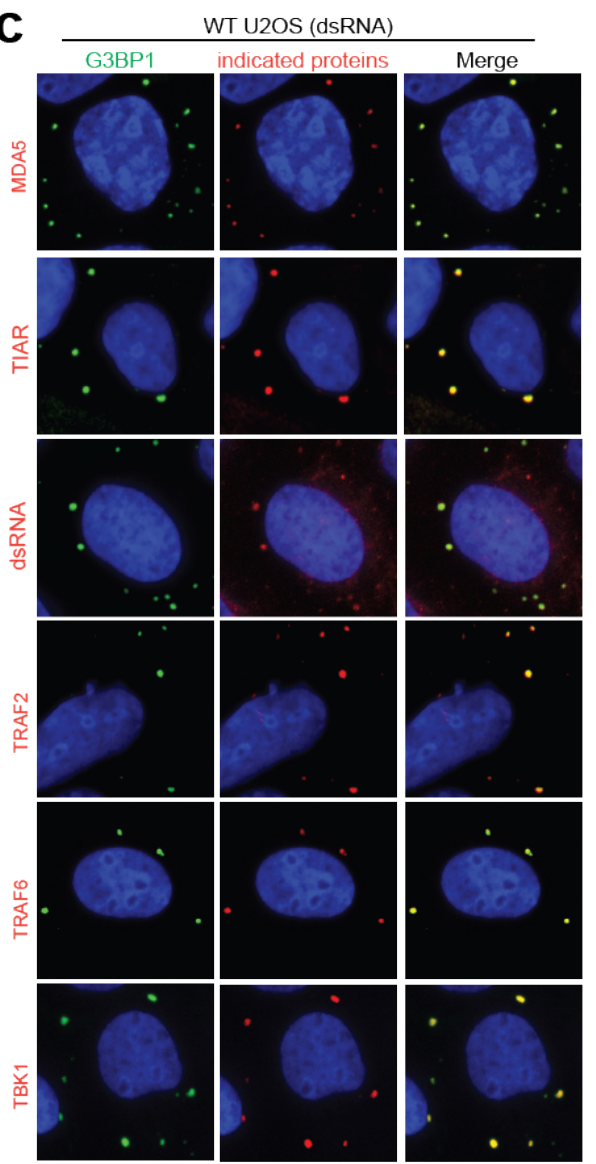
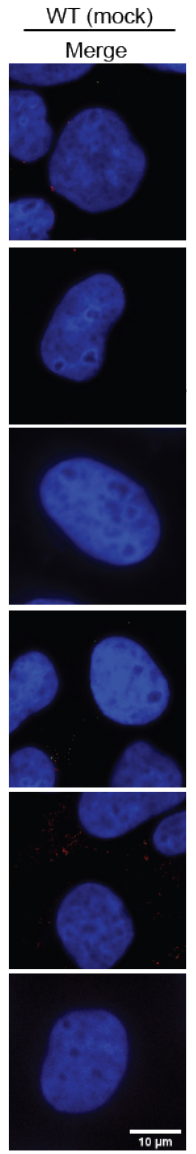

ED Fig 1. RLR-MAVS signalosomes and downstream innate immune molecules colocalize with SGs upon dsRNA stimulation.

a. Colocalization of RIG-I and MAVS with G3BP1 (green) in A549 cells (top) and HeLa cells (bottom), as examined by immunofluorescence assay. Cells were stimulated with $162 \mathrm{bp}$ dsRNA containing 5'ppp (500 ng/ml) for $6 \mathrm{hr}$. Nuclei were stained with Hoechst 3342.

b. Validation of antibodies for G3BP1, RIG-I and MAVS using individual knockout U2OS cells. Cells were stimulated with $162 \mathrm{bp}$ dsRNA $(500 \mathrm{ng} / \mathrm{ml})$ and imaged at $6 \mathrm{hr}$ postdsRNA as in (a).

c. Colocalization of MDA5, TIAR, dsRNA, TRAF2, TRAF6 and TBK1 (red) with G3BP1 (green) at $6 \mathrm{hr}$ post-dsRNA in U2OS cells. For dsRNA imaging, cells were stimulated 
with 162 bp dsRNA 3'-labeled with Cy3 and imaged using Cy3 fluorescence at 6 hr postdsRNA.

All data are representative of at least three independent experiments. Images were taken from representative field of view (FOV). All images were captured at $40 \mathrm{X}$ magnification except for the one for dsRNA, which was at 60X magnification. 
bioRxiv preprint doi: https://doi.org/10.1101/2021.04.26.441141; this version posted April 27, 2021. The copyright holder for this preprint (which was not certified by peer review) is the author/funder. All rights reserved. No reuse allowed without permission.

a
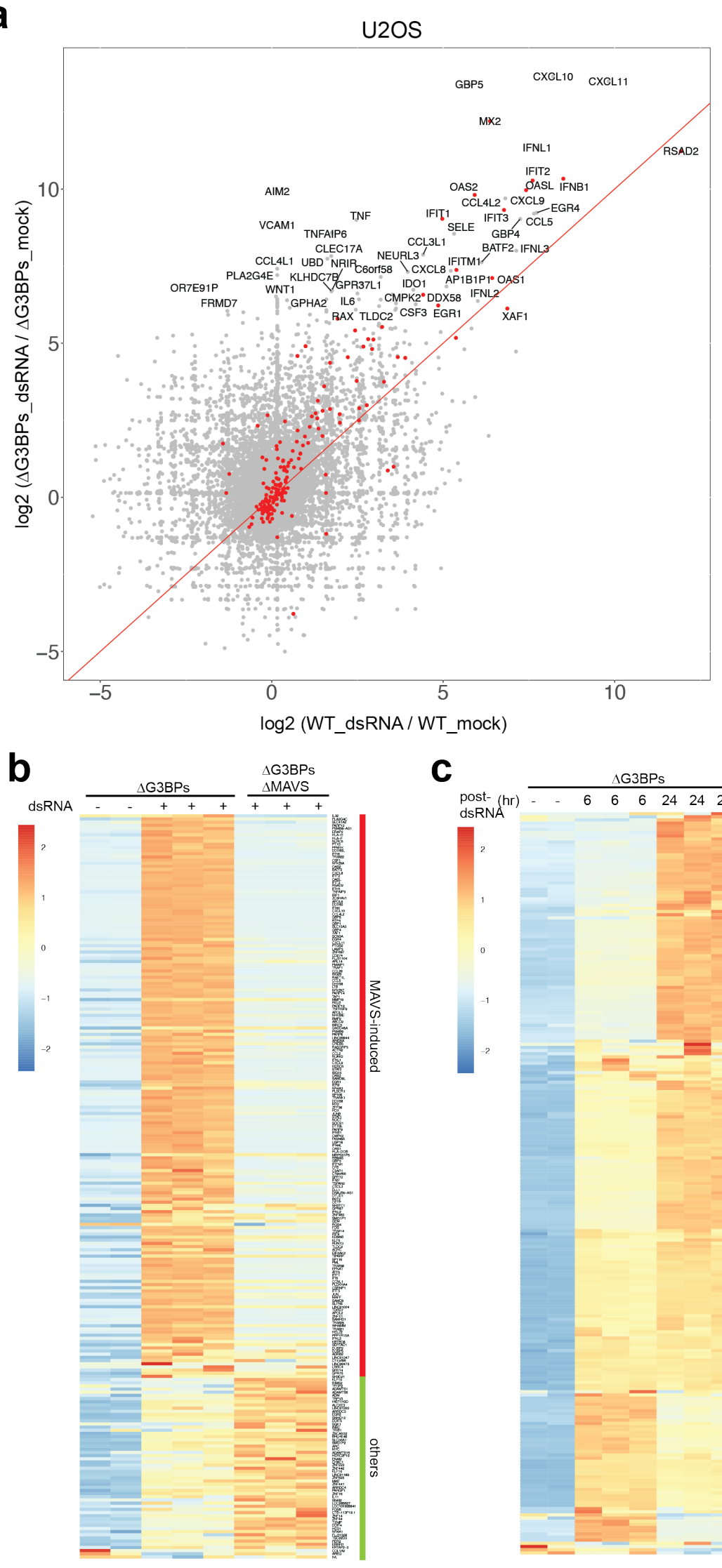

C
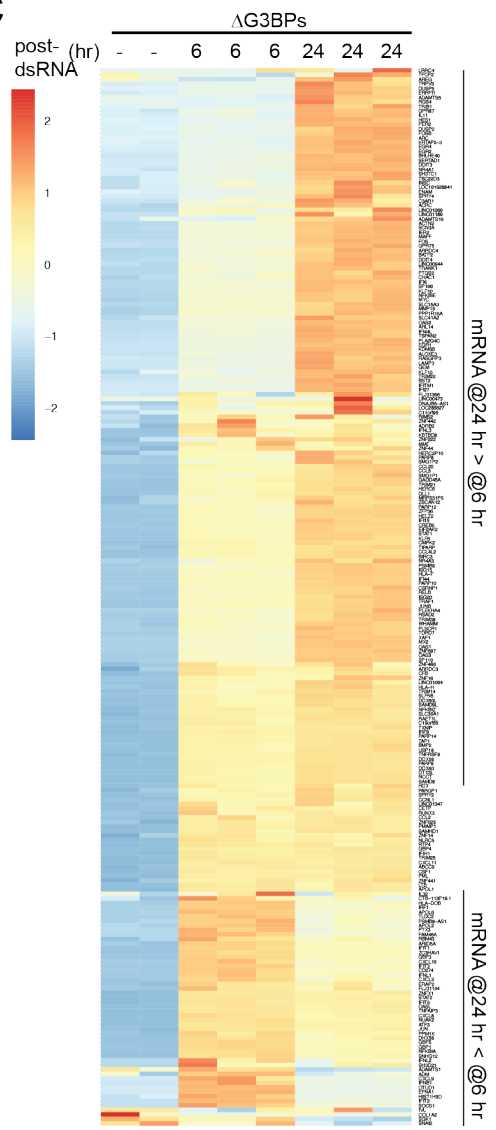
ED Fig 2. RLR-MAVS signaling is hyperactive in SG-deficient U2OS $\Delta$ G3BPs cells.

a. Scatter plot of log2-fold change (lfc2) upon dsRNA stimulation for $6 \mathrm{hr}$. Lfc2 values in U2OS WT were plotted against those in $\triangle$ G3BPs cells. Differentially expressed genes with lfc $2>6$ in $\triangle \mathrm{G} 3 \mathrm{BP}$ cells are labeled. Genes annotated as "type I interferon production" (GO:0032606) and "response to type I interferon" (GO:0034340) are colored red.

b. Heat map of z-scores for indicated genes from RNA-seq of U2OS $\Delta$ G3BP cells (with or without dsRNA treatment for $6 \mathrm{hr}$ ) and $\triangle$ G3BP $\triangle$ MAVS cells (with dsRNA treatment for $6 \mathrm{hr}$ ). Genes showing lfc $2>2$ (with $p \_$adj $<0.05$ ) upon dsRNA stimulation in WT cells were shown. Only MAVS-induced genes were shown in Figure 1d (in the same gene order).

c. Heat map of z-scores for indicated genes from RNA sequencing of U2OS $\triangle \mathrm{G} 3 B \mathrm{BP}$ cells treated with dsRNA for 6 or $24 \mathrm{hr}$; the indicated genes are from (b) and re-ordered by hierarchical clustering.

Raw data for the heatmaps can be found in the supplemental files (data 2 and 3 ). 

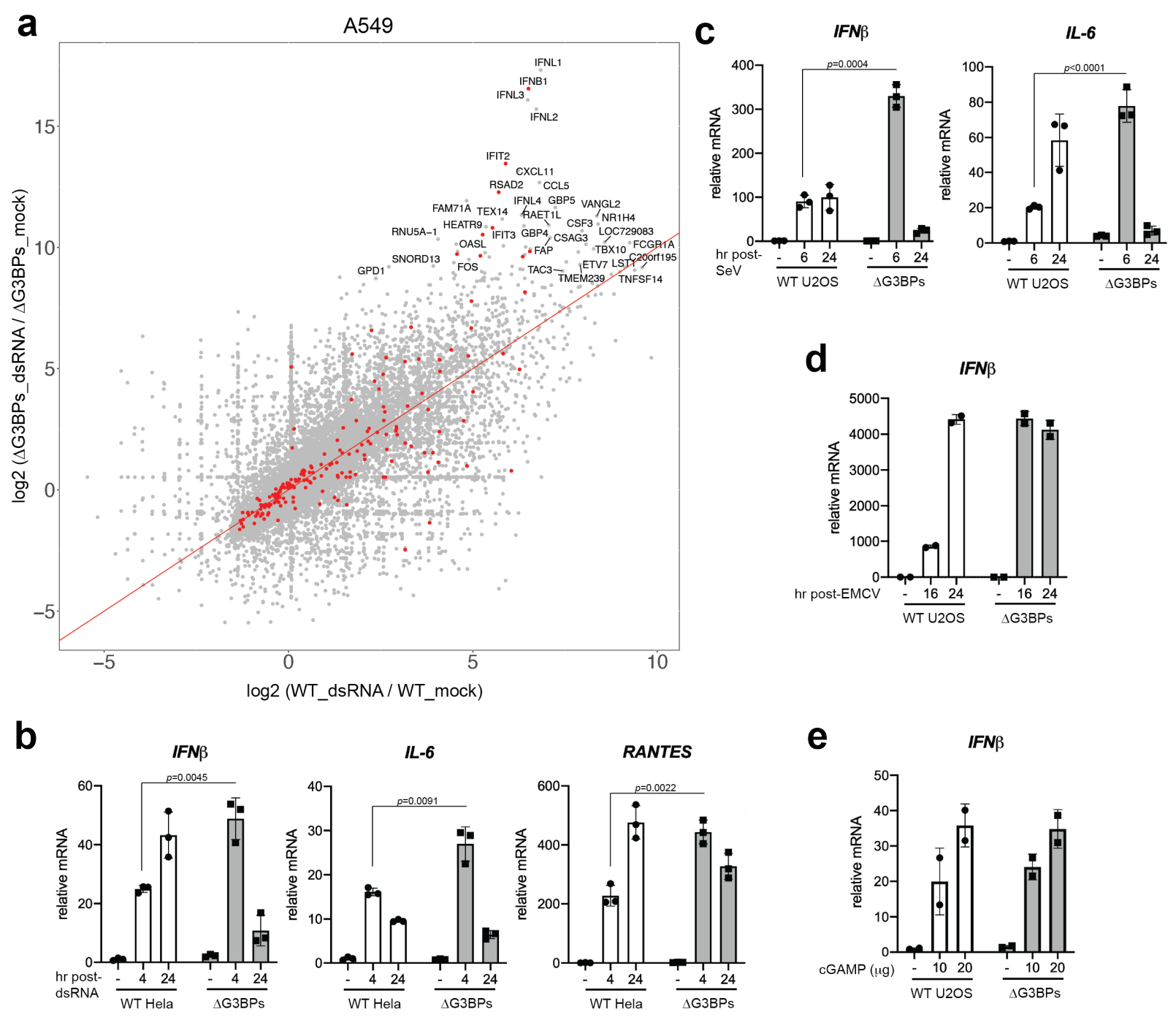

ED Fig 3. RLR-MAVS signaling is hyperactive in A549 $\Delta$ G3BPs and HeLa $\triangle$ G3BPs cells.

a. Scatter plot of log2-fold change (lfc2) upon dsRNA stimulation $(500 \mathrm{ng} / \mathrm{mL})$ for $4 \mathrm{hr}$. Lfc2 values in U2OS A549 were plotted against those in $\triangle$ G3BPs cells. Differentially expressed genes with 1fc $2>9$ in $\triangle \mathrm{G} 3 \mathrm{BP}$ cells are labeled. Genes annotated as "type I interferon production" (GO:0032606) and "response to type I interferon" (GO:0034340) are colored red.

b. Antiviral signaling in HeLa cells (WT vs $\triangle \mathrm{G} 3 \mathrm{BPs}$ ), as measured by the level of IFN $\beta$ (left), IL-6 (middle), and RANTES (right) mRNAs. Cells were stimulated with $162 \mathrm{bp}$ dsRNA with 5 'ppp (500 ng/ml) for 4 or $24 \mathrm{hr}$.

c. Antiviral signaling in U2OS cells (WT vs $\Delta$ G3BPs) in response to $\mathrm{SeV}(100 \mathrm{HA} / \mathrm{ml})$, as measured by the level of $I F N \beta$ (left) and $I L-6$ (right) mRNAs at 6 or $24 \mathrm{hr}$ post-infection.

d. Antiviral signaling in U2OS cells (WT vs $\triangle \mathrm{G} 3 \mathrm{BPs}$ ) in response to EMCV (MOI 0.1), as measured by the level of IFN $\beta$ mRNA at 16 or $24 \mathrm{hr}$ post-infection. 
e. Antiviral signaling in U2OS cells (WT vs $\triangle \mathrm{G} 3 \mathrm{BPs}$ ) in response to $2^{\prime} 3^{\prime}$-Cyclic GMPAMP (cGAMP, 10 or $20 \mu \mathrm{g}$ ), as measured by the level of IFN $\beta$ mRNAs at 6 hr posttreatment.

Data in (b-c) are presented in means \pm SD $(n=3)$. Data in (d-e) are presented in means \pm SD $(n=2)$. Data are representative of three independent experiments. $p$ values were calculated using the two-tailed unpaired Student's t test. 
a
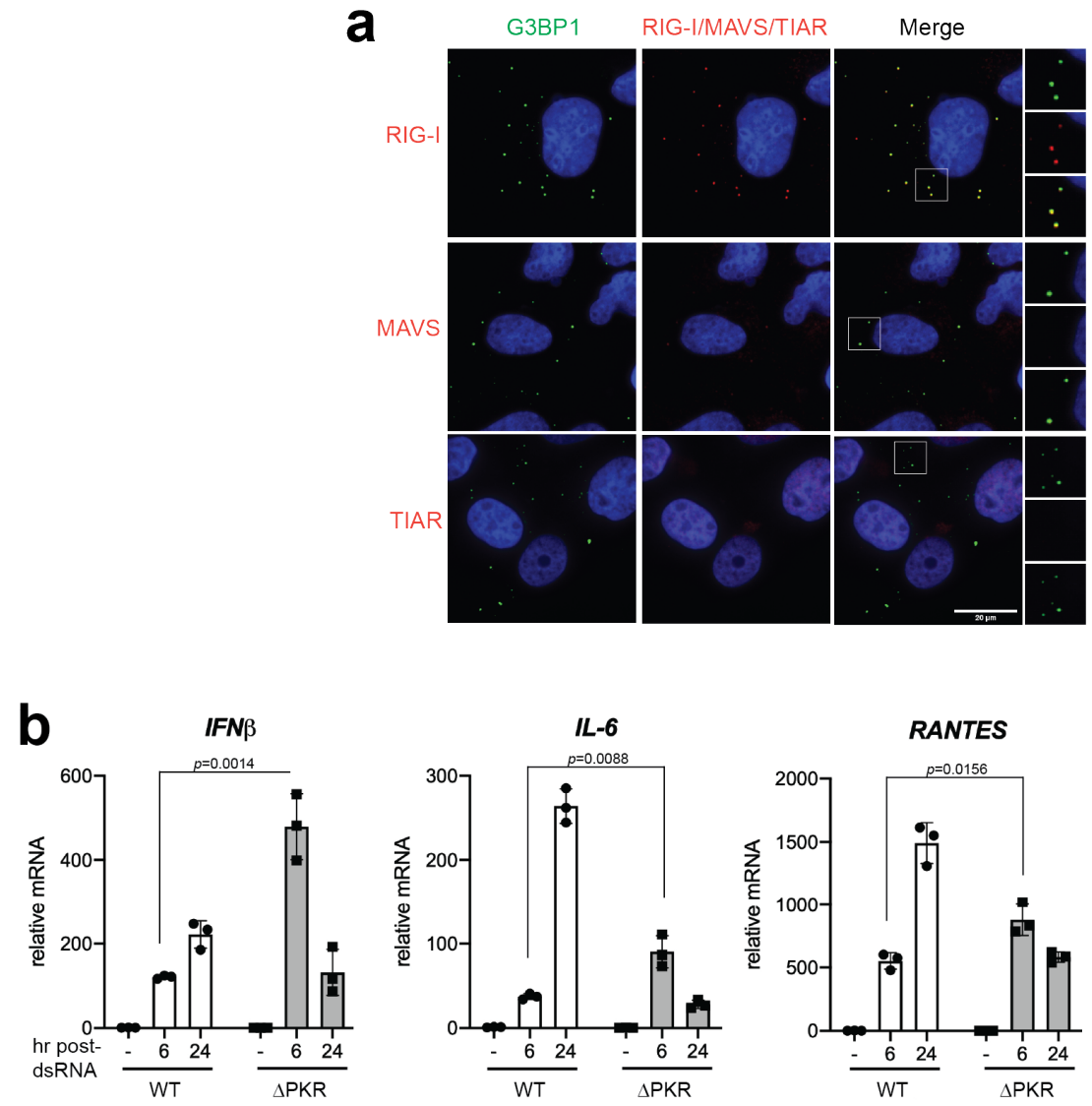
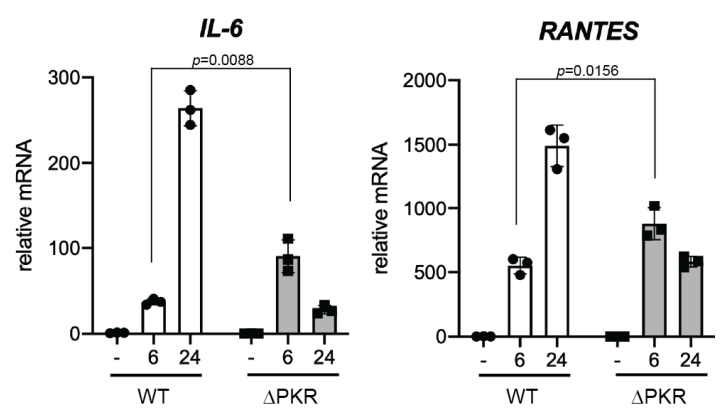
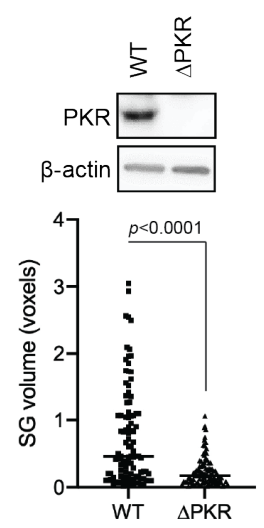

C

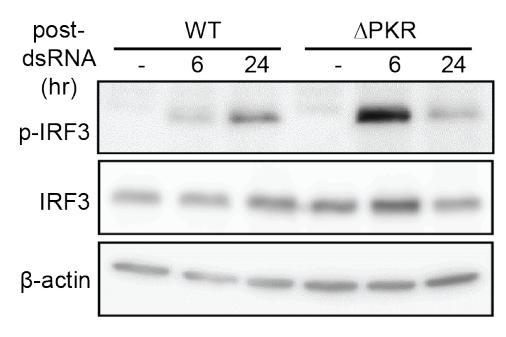

ED Fig S4. PKR is required for dsRNA-induced SG formation and suppression of RLR signaling.

a. Colocalization of RIG-I, MAVS and TIAR (red) with G3BP1 (green) in U2OS $\triangle$ PKR cells. Cells were transfected with 162 bp dsRNA with 5 'ppp at $500 \mathrm{ng} / \mathrm{ml}$ for $6 \mathrm{hr}$. Insets show SGs at higher magnifications. To determine the SG size (right), Z-stack images $(0.15 \mu \mathrm{m}$ step size $)$ were obtained using a Nikon TI2 motorized inverted microscope. All images were taken with a 60x oil-immersion lens at 60x magnification. SG size was quantitated from at least 3 separate FOV using the ImageJ 3D Objects counter. Size distribution (voxels) of randomly selected 100 granules was plotted on the right.

b. Antiviral signaling in U2OS cells (WT vs $\triangle \mathrm{PKR}$ ) in response to dsRNA $(500 \mathrm{ng} / \mathrm{ml})$, as measured by the level of IFN $\beta$ (left), IL-6 (center) and RANTES (right) mRNAs at 6 or 24 hr post-dsRNA.

c. IRF3 phosphorylation in U2OS cells (WT vs $\triangle \mathrm{PKR}$ ). Cells were stimulated as in (b).

Data in (b) are presented in means $\pm \mathrm{SD}(\mathrm{n}=3)$. Data are representative of three independent experiments. $p$ values were calculated using the two-tailed unpaired Student's test. 
a
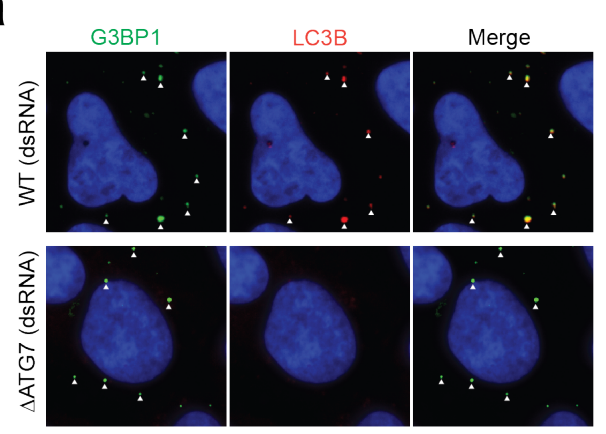

C

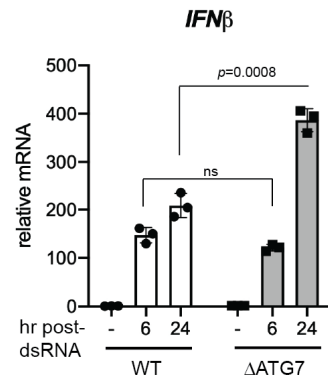

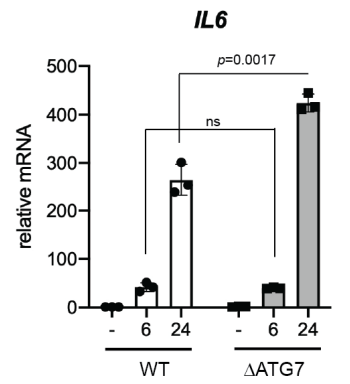

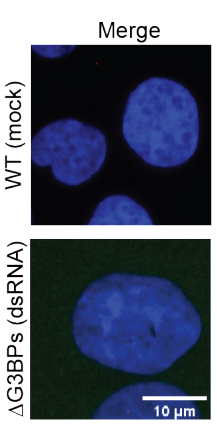

b
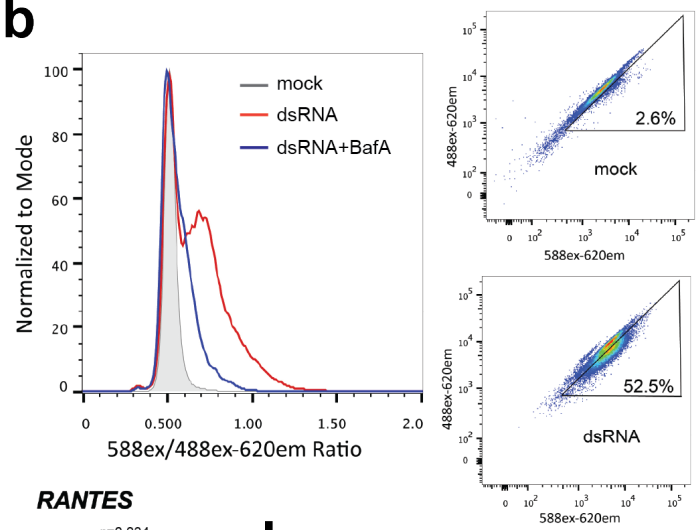

RANTES

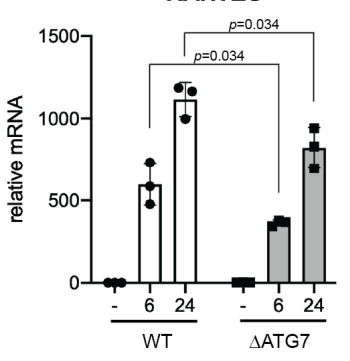

Q

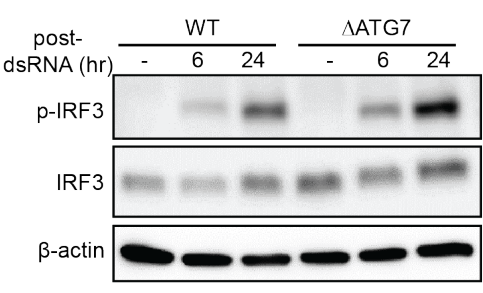

e

WT/KO U2OS

(+/- dsRNA stimulation) WT U2OS (resting)

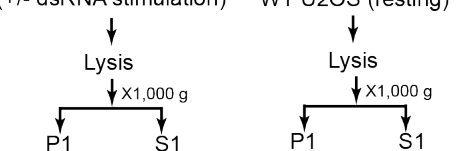

$\begin{array}{cc}\mathrm{P} 1 & \mathrm{~S} 1 \\ \text { (nucleus) } & \text { (cytoplasm) }\end{array}$

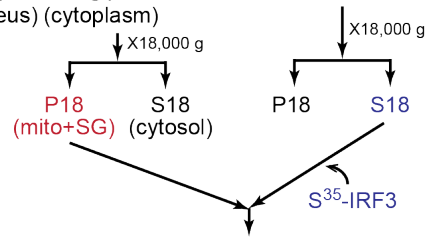

monitor IRF3 dimerization

f
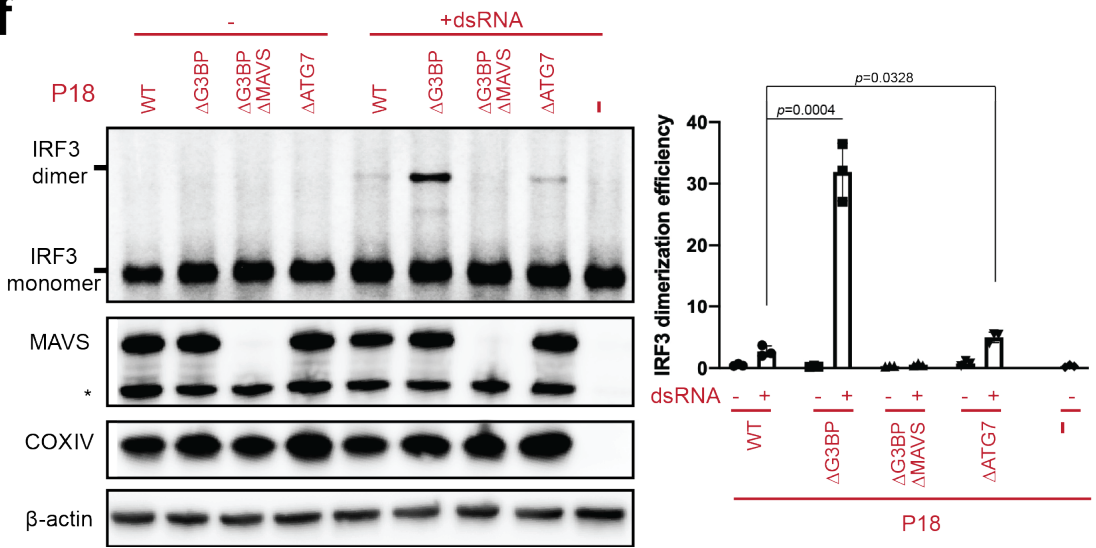

Figure 2. dsRNA-induced SGs are targeted by autophagy, which together suppress RLR signaling.

a. Colocalization of LC3B (red) with G3BP1 (green) in U2OS cells (WT vs autophagydeficient $\triangle \mathrm{ATG} 7$ and SG-deficient $\triangle \mathrm{G} 3 \mathrm{BPs}$ ) as analyzed by immunofluorescence. Arrows indicate examples of SGs. Cells were stimulated with 162 bp dsRNA containing 5 'ppp (500 ng/ml) for $6 \mathrm{hr}$. Manders overlap coefficient for LC3B and G3BP1 is 0.84 in WT cells and 0.28 in $\triangle \mathrm{ATG} 7$ cells.

b. FACS analysis of keima-RIG-I. Keima-RIG-I was expressed in A549 cells under the control of doxycycline $(1 \mu \mathrm{g} / \mathrm{ml})$. Cells were transfected with $162 \mathrm{bp}$ dsRNA containing 5'ppp (1500 ng/ml) and subsequently treated with BafA $(100 \mathrm{nM})$ or DMSO at $4 \mathrm{hr}$ postdsRNA. Cells were analyzed $16 \mathrm{hr}$ post-dsRNA. Cell population showing a spectral shift indicative of acidification is shown in triangle (right). The ratio of Keima excitation at $588 \mathrm{~nm} / 488 \mathrm{~nm}$ was shown on the left. 
c. Antiviral signaling in U2OS cells (WT vs $\triangle \mathrm{ATG} 7$ ), as measured by the level of IFN $\beta$ (left), IL-6 (middle), and RANTES (right) mRNAs. Cells were stimulated with $162 \mathrm{bp}$ dsRNA with 5 'ppp $(500 \mathrm{ng} / \mathrm{ml})$ for 6 or $24 \mathrm{hr}$.

d. IRF3 phosphorylation in U2OS cells (WT vs $\triangle$ ATG7). Cells were stimulated for 6 and 24 hr with 162 bp dsRNA containing 5'ppp (500 ng/ml).

e. Schematic of the cell-free IRF3 dimerization assay. Mitochondrial/SG fraction (P18) containing MAVS was isolated from various U2OS cells with and without dsRNA, and then mixed with a common pool of cytosolic extract (S18) from unstimulated WT U2OS cells and in vitro translated $S^{35}$-IRF3. Dimerization of $S^{35}$-IRF3 was measured by native gel assay.

f. Cell-free IRF3 dimerization assay. P18 was prepared from WT, $\triangle \mathrm{G} 3 \mathrm{BPs}$, $\triangle$ G3BPs $\triangle$ MAVS and $\triangle$ ATG7 U2OS cells pre-stimulated with dsRNA as in (e). The level of dimerized IRF3 was quantitated from three independent measurements (right). The levels of COXIV and MAVS were analyzed to ensure that an equivalent amount of mitochondria is present in P18 fractions. Actin was used as an internal control for cytosolic fraction (S18).

Data in (c) and (f) are presented in means $\pm \mathrm{SD}(\mathrm{n}=3)$. Data are representative of three independent experiments. $p$ values were calculated using the two-tailed unpaired Student's t test (ns, $p>0.05$ ). 


\section{a}
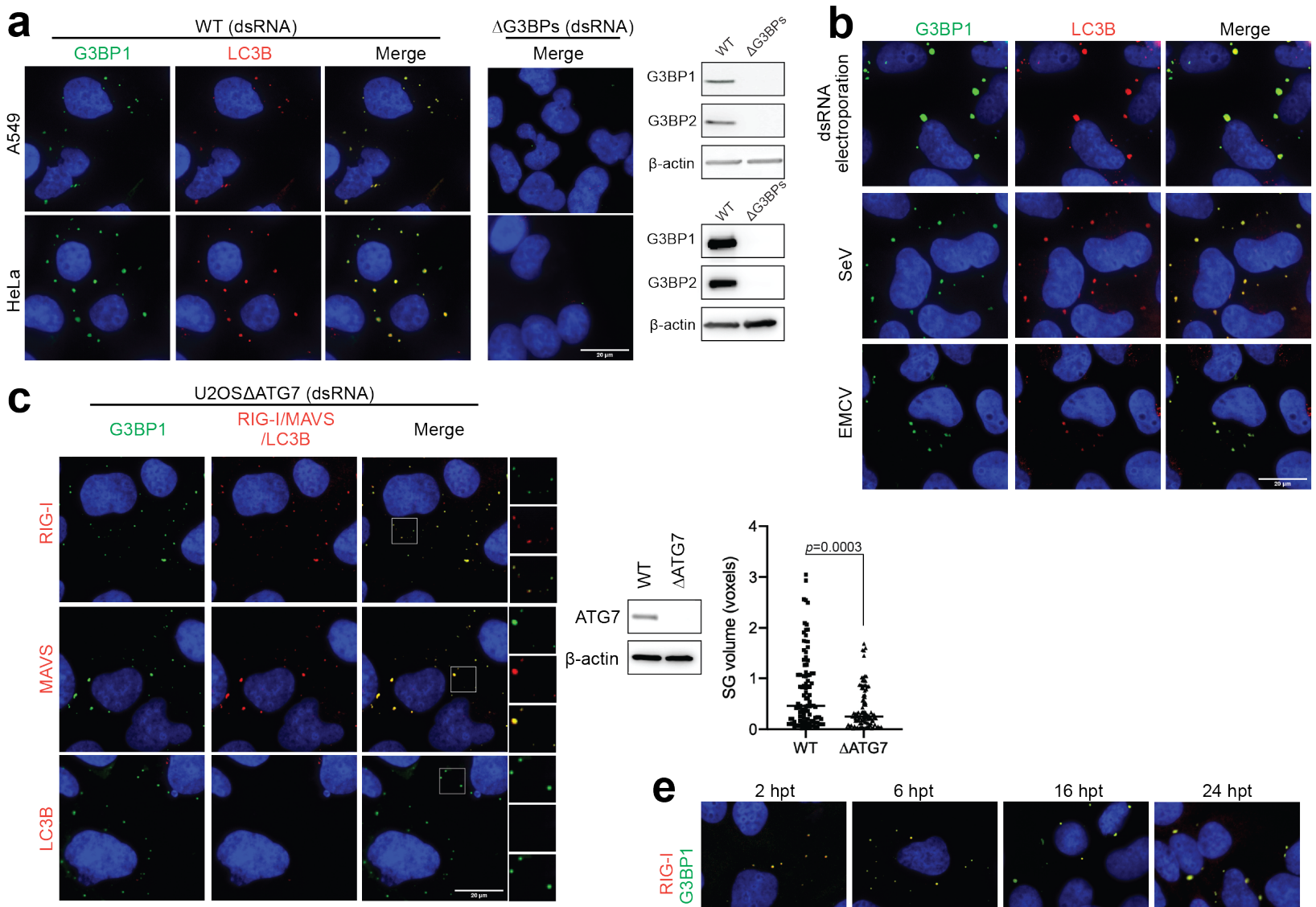

d

G3BP1

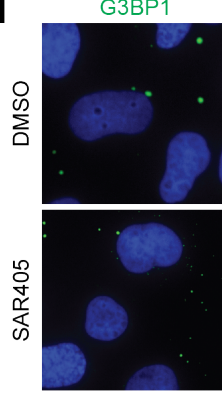

LC3B

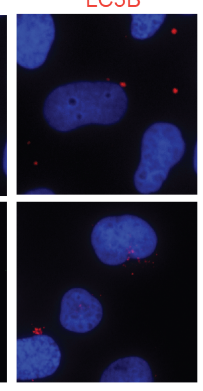

Merge

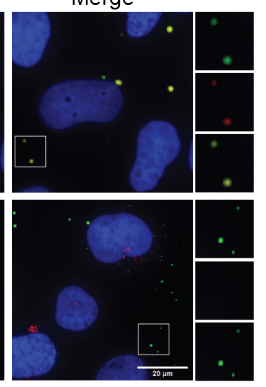

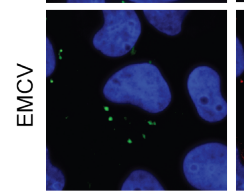
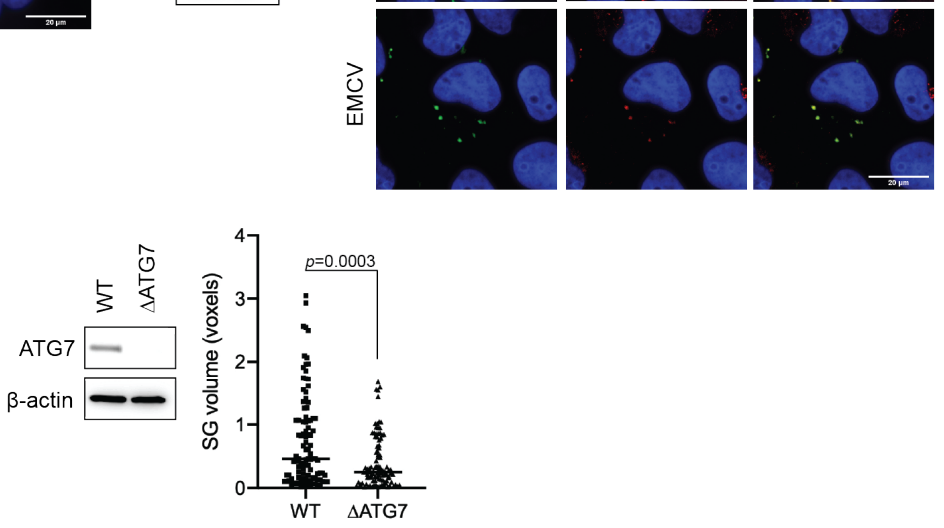

$\mathbf{e}$
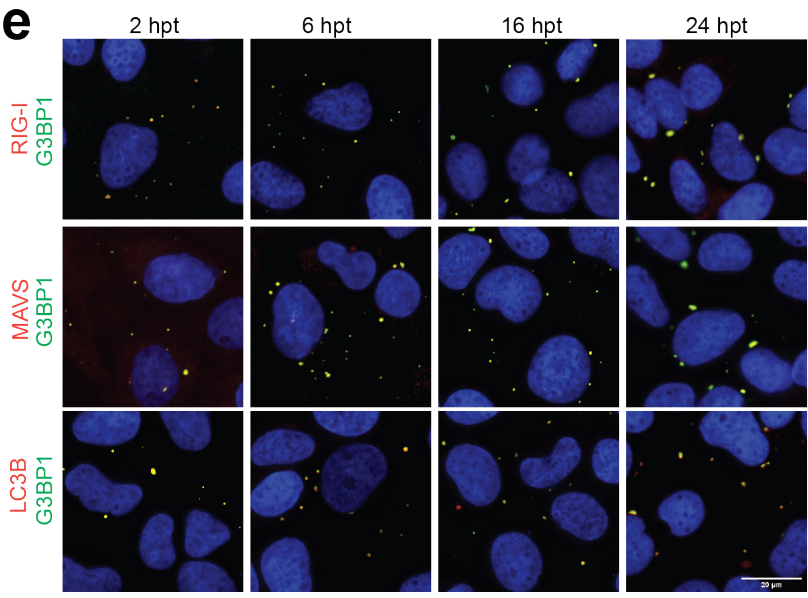

ED Fig 5. SGs undergo autophagy, whether they are induced by dsRNA or viruses.

a. Colocalization of LC3B (red) with G3BP1 (green) in A549 cells and HeLa cells (WT vs SG-deficient $\triangle$ G3BPs) as analyzed by immunofluorescence. Cells were stimulated with $162 \mathrm{bp}$ dsRNA containing 5'ppp (500 ng/ml) for $6 \mathrm{hr}$.

b. SG localization of LC3B in U2OS cells upon electroporation with dsRNA or infection with EMCV or SeV. Colocalization of LC3B (red) with G3BP1 (green) was determined by immunofluorescence. Cells were electroporated with $162 \mathrm{bp}$ dsRNA containing 5'ppp $(2000 \mathrm{ng} / \mathrm{ml})$ for $8 \mathrm{hr}$ or infected with SeV (100 HA/ml) and EMCV (MOI of 0.1) for 16 and $8 \mathrm{hr}$, respectively. The viral dose and time of analysis were chosen to avoid virally induced cytotoxicity while maximizing visibility of SGs.

c. Colocalization analysis of RIG-I, MAVS and LC3B (red) with G3BP1 (green) in U2OS $\triangle \mathrm{ATG} 7$ cells upon dsRNA stimulation. Insets show SGs at higher magnifications. Cells were transfected with $162 \mathrm{bp}$ dsRNA containing 5'ppp (500 ng/ml) for $6 \mathrm{hr}$. The 
result shows that while SGs form in $\triangle \mathrm{ATG} 7$ cells, the granules are smaller than those in WT cells. To determine the SG size (bottom), Z-stack images $(0.15 \mu \mathrm{m}$ step size) were obtained using a Nikon TI2 motorized inverted microscope. All images were taken with a 60x oil-immersion lens. Stress granule size was quantitated from at least 3 separate FOV using the ImageJ 3D Objects counter. Size distribution (voxels) of randomly selected 100 granules was plotted.

d. Colocalization analysis of LC3B (red) with G3BP1 (green) in U2OS cells upon treatment with VPS inhibitor SAR405. Insets show SGs at higher magnifications. Cells were transfected with $162 \mathrm{bp}$ dsRNA containing 5'ppp (500 ng/ml), and then treated with SAR405 $(1 \mu \mathrm{M})$ at $2 \mathrm{hr}$ post-dsRNA. Cells were imaged $6 \mathrm{hr}$ post-dsRNA. The result shows that SGs can still form in the presence of SAR405 but fail to recruit LC3B.

e. Presence of SGs and autophagosomes in WT U2OS cells at indicated timepoints postdsRNA. Foci formation of RIG-I, MAVS, LC3B (red) and G3BP1 (green) was analyzed.

Data are representative of at least two independent experiments. $p$ values were calculated using the two-tailed unpaired Student's t test. 

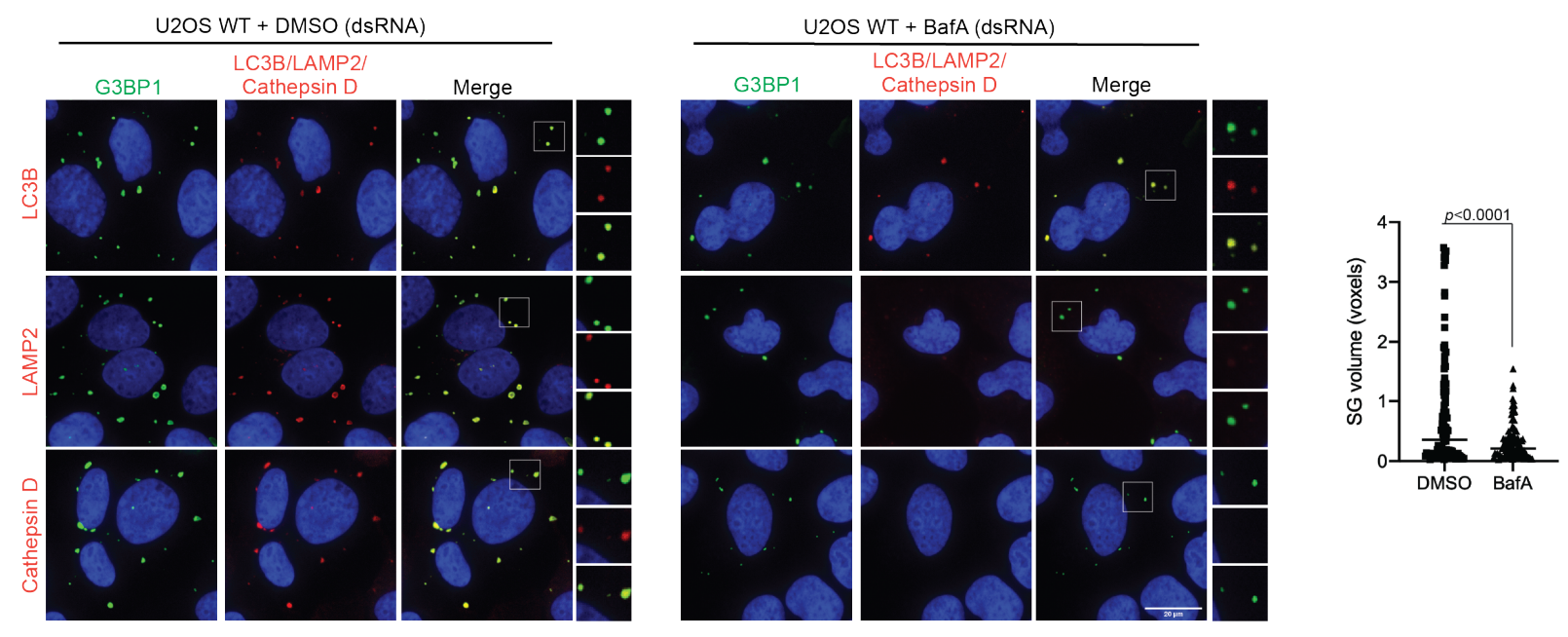

ED Fig 6. dsRNA-induced SGs are incorporated into autolysosome. Colocalization of LC3B, LAMP2 and Cathepsin D (red) with G3BP1 (green) in U2OS WT cells in the presence and absence of bafilomycin A1 (BafA). Insets show SGs at higher magnifications. Cells were stimulated with $162 \mathrm{bp}$ dsRNA containing 5'ppp (500 ng/ml) for $6 \mathrm{hr}$. BafA $(50 \mathrm{nM})$ or DMSO was added $2 \mathrm{hr}$ post-dsRNA. BafA blocked SG localization of LAMP2 and Cathepsin D but not LC3B. While SGs still form in the presence of BafA, SGs are smaller than those in mock-treated cells. The SG size distribution in BafA-treated cells is similar to that in $\triangle \mathrm{ATG} 7$ cells, which suggests that SGs grow in size upon autolysosome formation. Data are representative of three independent experiments. $p$ values were calculated using the two-tailed unpaired Student's t test. 

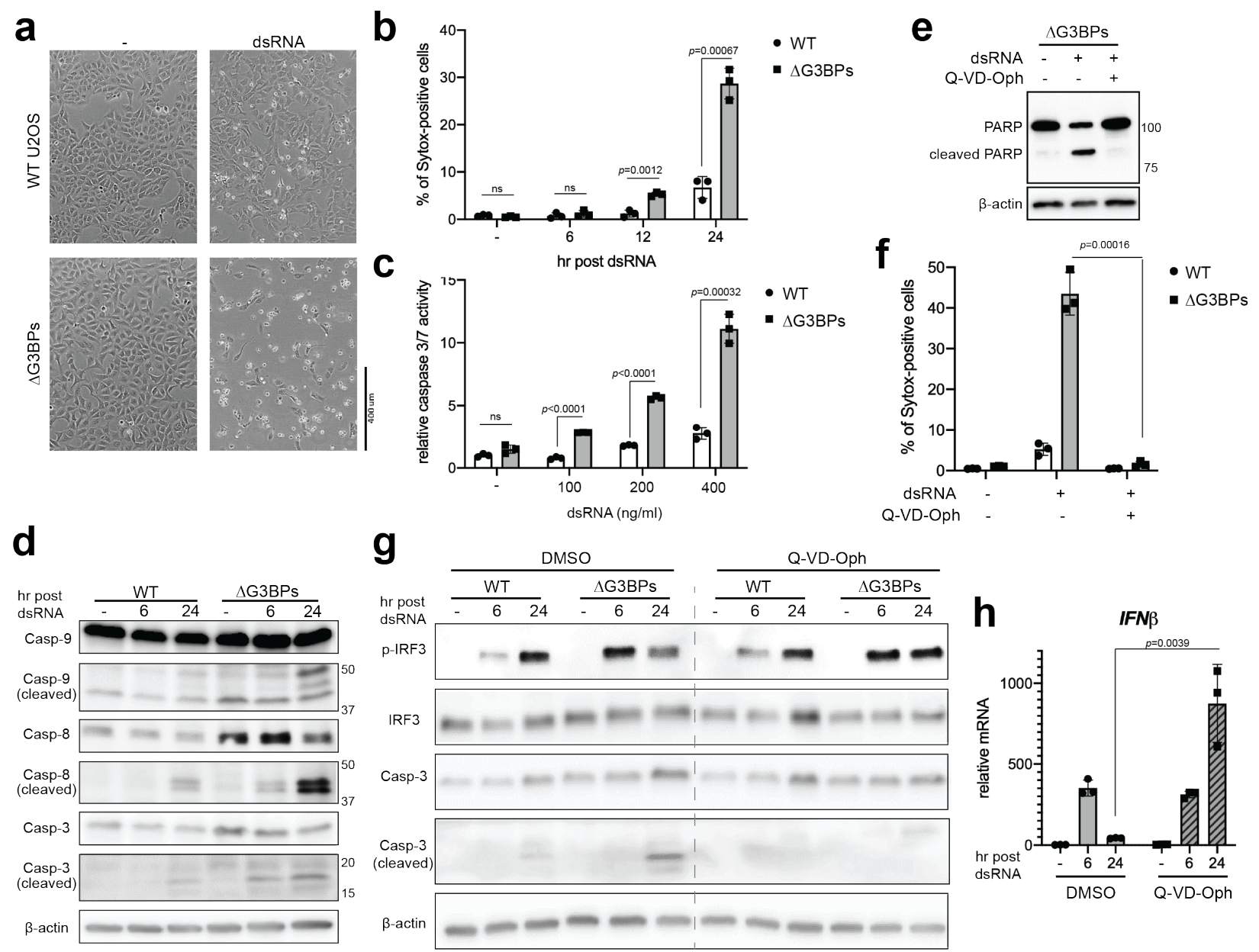

Figure 3. SGs dampen dsRNA-triggered apoptosis and the consequent negative feedback regulation of IRF3.

a. Cell death in WT vs. $\triangle$ G3BPs U2OS cells as examined by bright-field microscopy. Cells were stimulated with $162 \mathrm{bp}$ dsRNA as in Figure $1 \mathrm{~b}$ and analyzed at $24 \mathrm{hr}$ post-dsRNA.

b. Cell death in WT vs. $\triangle$ G3BPs U2OS as measured by Sytox uptake at indicated time postdsRNA (500 ng/ml) stimulation. Percentage of Sytox-positive cells among Hoechst 3342 (nuclear stain)-positive cells was plotted.

c. Caspase-3/7 activity of WT vs. $\Delta$ G3BPs U2OS cells at $24 \mathrm{hr}$ post-transfection of dsRNA at indicated concentrations. Caspase-3/7 activity was determined as a ratio of Caspase $3 / 7$ stain-positive cells to Hoechst 3342-positive cells.

d. Apoptotic caspase cleavage in WT vs $\triangle$ G3BPs U2OS cells at 6 or $24 \mathrm{hr}$ post-dsRNA.

e. PARP cleavage in U2OS $\triangle$ G3BPs cells $24 \mathrm{hr}$ post-dsRNA in the presence and absence of the pan-caspase inhibitor Q-VD-OPh $(10 \mu \mathrm{M})$. Cells were treated with Q-VD-OPh $1 \mathrm{hr}$ pre-dsRNA.

f. Cell death in WT vs. $\triangle$ G3BPs U2OS cells as measured by Sytox uptake at $24 \mathrm{hr}$ postdsRNA in the presence and absence of Q-VD-OPh $(10 \mu \mathrm{M})$.

g. Effect of Q-VD-OPh $(10 \mu \mathrm{M})$ on IRF3 phosphorylation and caspase-3 cleavage.

h. Effect of Q-VD-OPh $(10 \mu \mathrm{M})$ on $I F N \beta$ mRNA induction in $\triangle \mathrm{G} 3 \mathrm{BPs}$ U2OS cells. 
bioRxiv preprint doi: https://doi.org/10.1101/2021.04.26.441141; this version posted April 27, 2021. The copyright holder for this preprint (which was not certified by peer review) is the author/funder. All rights reserved. No reuse allowed without permission.

Data in (b-c), (f) and (h) are presented in means \pm SD, where $n=3 . p$ values were calculated using the two-tailed unpaired Student's t test (ns, $p>0.05$ ). 
a
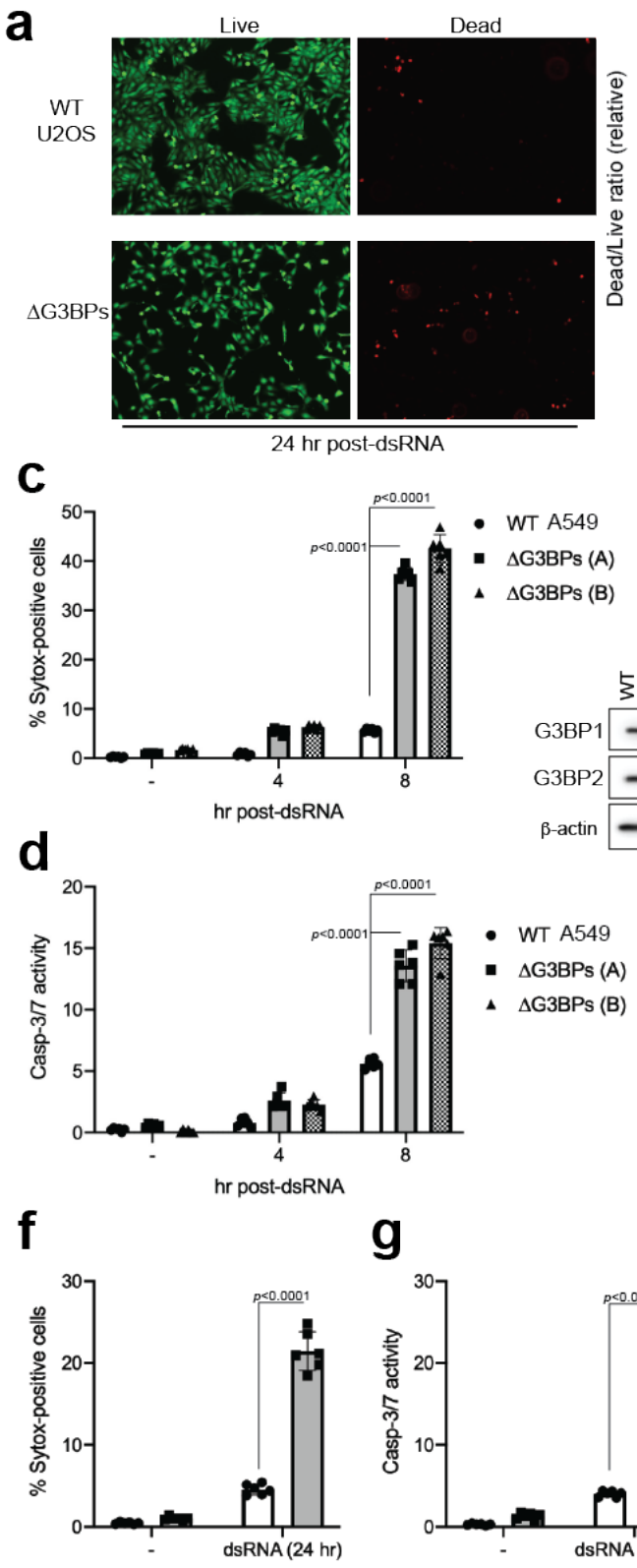

g

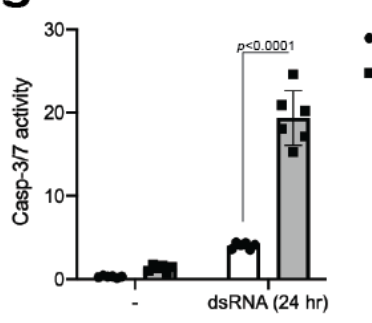

b
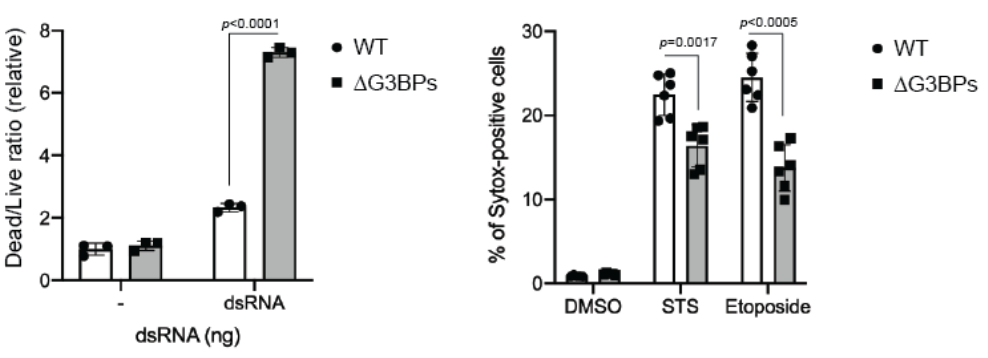

$\mathbf{e}$

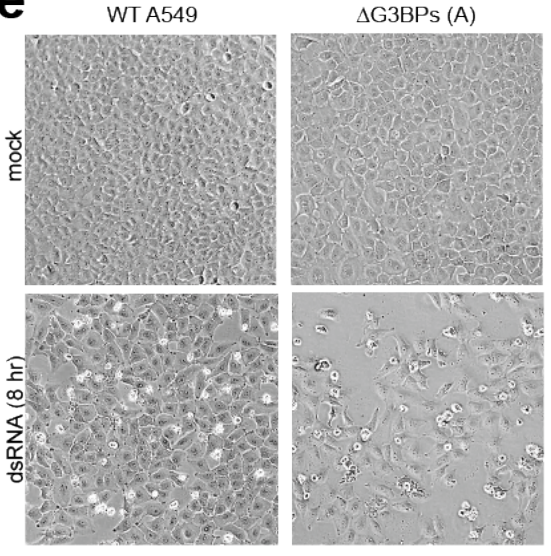

h
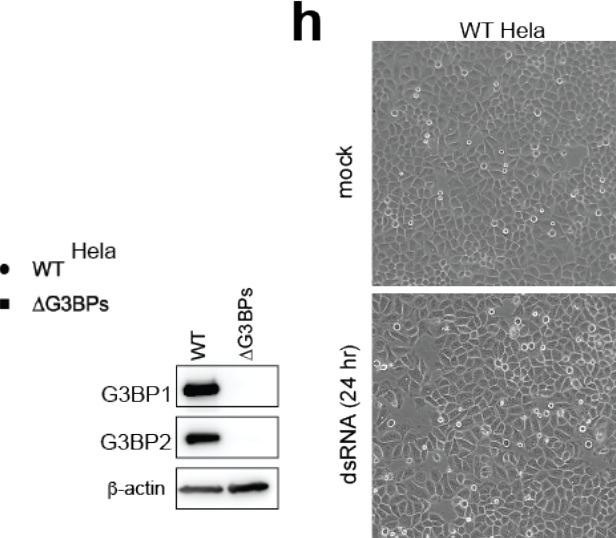

$\triangle \mathrm{G} 3 \mathrm{BPS}(\mathrm{B})$

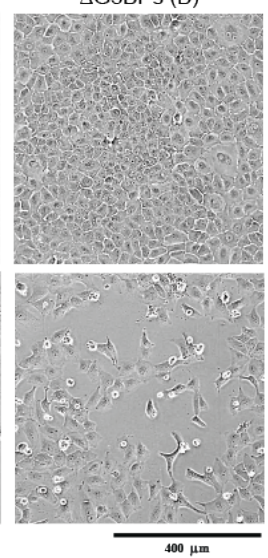

$\triangle \mathrm{G} 3 \mathrm{BPs}$

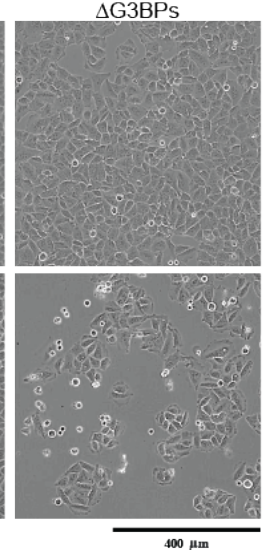

ED Fig 7. SG deficiency results in more pronounced apoptosis in U2OS, A549 and HeLa cells upon dsRNA stimulation.

a. Cell death in WT vs. $\triangle$ G3BPs U2OS cells in response to $162 \mathrm{bp}$ dsRNA transfection (500 $\mathrm{ng} / \mathrm{ml}$ ). Cells were stained with the LIVE/DEAD ${ }^{\circledR}$ Viability/Cytotoxicity stain (Thermo) $24 \mathrm{hr}$ post-dsRNA and were imaged using a Nikon Eclipse TS2R inverted microscope (left). The ratio of dead to live cells were determined by dividing the DEAD stain intensity (red) by LIVE stain intensity (green) as quantitated by ImageJ (right).

b. Cell death in WT vs $\triangle$ G3BPs U2OS cells in response to staurosporin (STS) and epotoside, as measured by Sytox uptake. Cells were stimulated with STS $(1 \mu \mathrm{M})$ or etoposide $(20 \mu \mathrm{M})$ for $24 \mathrm{hr}$ before stained with Sytox for imaging. Percentage of Sytoxpositive cells among Hoechst 3342 (nuclear stain)-positive cells was plotted. 
c-e. Cell death in WT vs. $\triangle$ G3BPs A549 cells in response to 162 bp dsRNA transfection (500 $\mathrm{ng} / \mathrm{ml})$. Two independent clones of $\Delta \mathrm{G} 3 B \mathrm{BPs}$ were analyzed. Cell death was measured at 8 hr post-dsRNA by Sytox uptake (c), caspase 3/7 activity assay (d) and brightfield microscopy (e).

f-h. Cell death in WT vs. $\triangle$ G3BPs HeLa cells in response to $162 \mathrm{bp}$ dsRNA transfection (500 $\mathrm{ng} / \mathrm{ml}$ ). Cell death was measured at $24 \mathrm{hr}$ post-dsRNA by Sytox uptake (f), caspase 3/7 activity assay (g) and brightfield microscopy (h).

Data in (a-d) \& (f-g) are presented in means $\pm S D$, where $n=3$ for (a) and $n=6$ for the rest. All data are representative of at least three independent experiments. $p$ values were calculated using the two-tailed unpaired Student's t test (ns, $p>0.05$ ). 
a

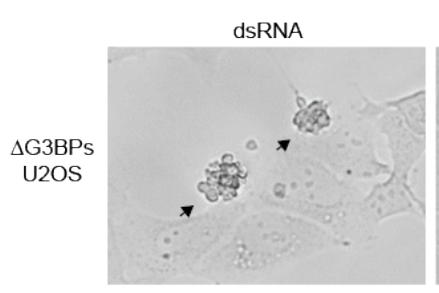

b
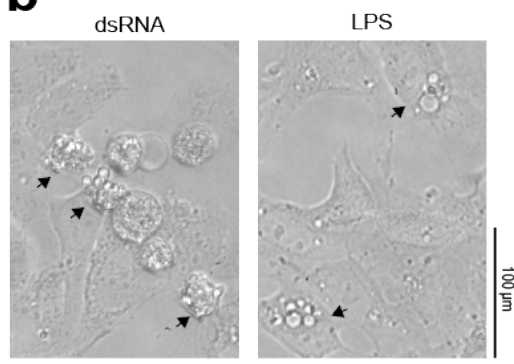

e

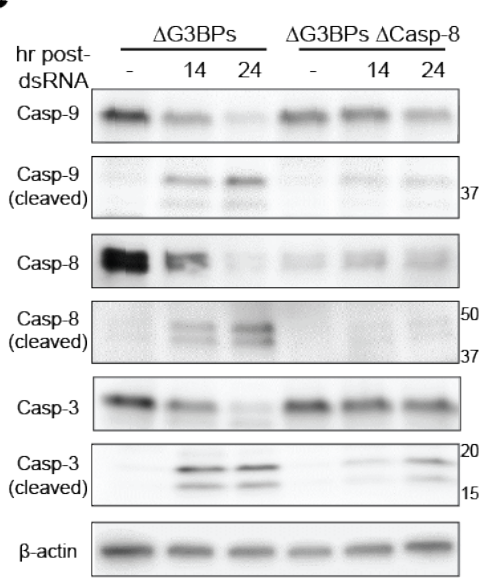

f

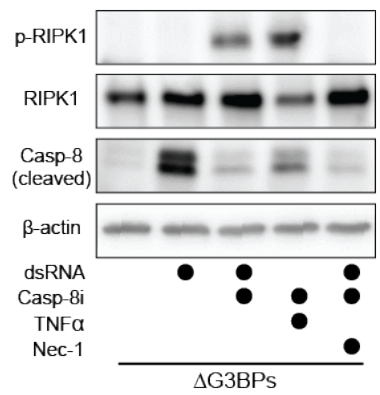

Etoposide

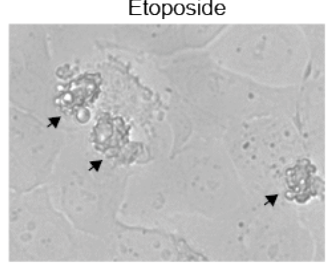

C

hr post-dsRNA

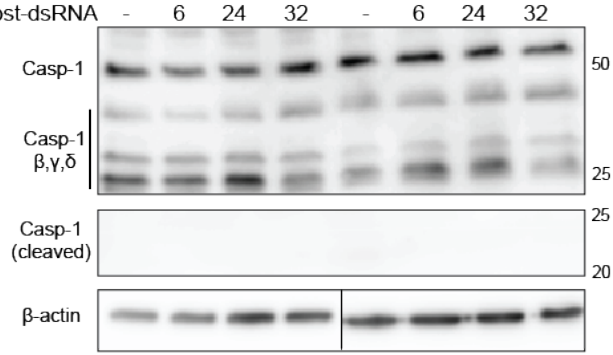

Casp-8i $+\mathrm{TNF \alpha}$

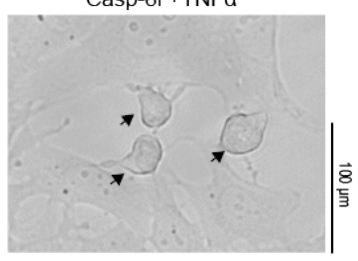

g
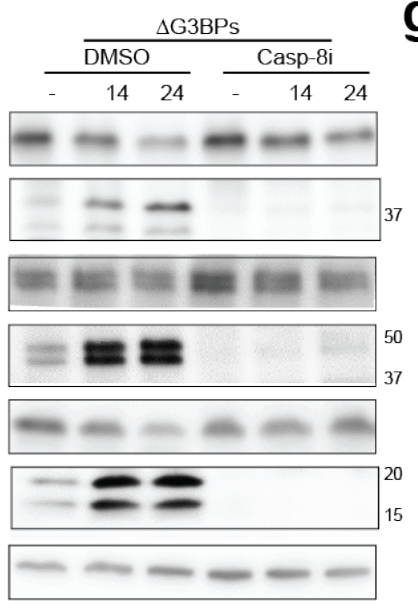

h

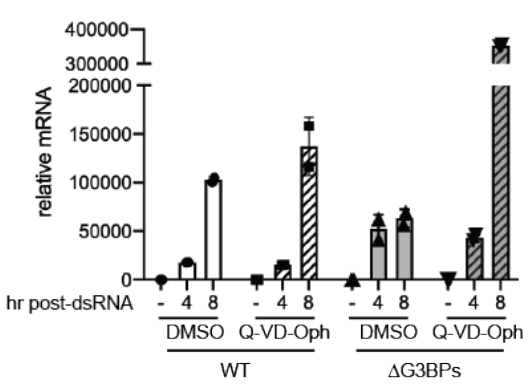

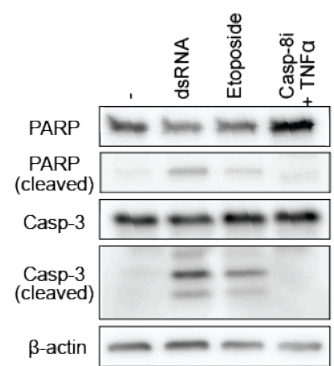

d

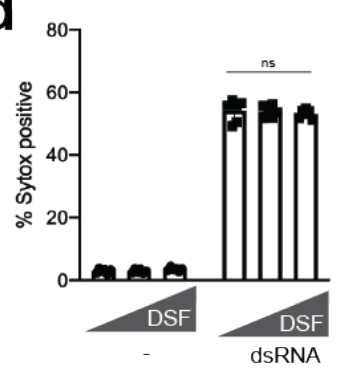

ED Fig 8. $\triangle$ G3BPs cells undergo caspase-8-dependent apoptosis, which suppresses IRF3 signaling in late stages.

a. Comparison of cell death triggered by dsRNA, etoposide and a combination of caspase- 8 inhibitor (Z-IETD-FMK) and TNF $\alpha$. Etoposide was used as a known trigger for apoptosis, while the combination of Z-IETD-FMK and TNF $\alpha$ was for necroptosis. 
U2OS $\triangle$ G3BPs cells were treated with $162 \mathrm{bp}$ dsRNA $(500 \mathrm{ng} / \mathrm{ml})$, etoposide $(20 \mu \mathrm{M})$ or Z-IETD-FMK $(50 \mu \mathrm{M})$ plus TNF $\alpha(20 \mathrm{ng} / \mathrm{ml})$. Microscopy images were taken at $100 \mathrm{X}$ magnification using a Nikon Eclipse TS2R inverted microscope $24 \mathrm{hr}$ post-treatment (left). Arrows indicate dying cells. Cleavage of PARP and caspase 3 was examined by WB (right).

b. Comparison of cell death triggered by dsRNA and LPS. U2OS $\triangle$ G3BPs cells were transfected with dsRNA $(500 \mathrm{ng} / \mathrm{ml})$ or LPS $(2 \mu \mathrm{g} / \mathrm{ml})$ and cells were imaged $24 \mathrm{hr}$ posttransfection. Cytosolic LPS was used as a known trigger for pyroptosis. Arrows indicate dying cells.

c. Caspase-1 cleavage analysis in WT and $\triangle$ G3BPs U2OS cells upon 162 bp dsRNA (500 $\mathrm{ng} / \mathrm{ml}$ ) stimulation. Cells were harvested at the indicated time points and were subjected to WB analysis. No caspase-1 cleavage was observed in either WT or $\Delta \mathrm{G} 3 \mathrm{BP}$ s cells upon dsRNA transfection.

d. Effect of the gasdermin D inhibitor disulfiram (DFS) on dsRNA-induced cell death in U2OS $\Delta$ G3BPs. Cells were pre-treated with DMSO or with disulfiram $(10$ or $25 \mu \mathrm{M})$ and transfected with $162 \mathrm{bp}$ dsRNA (500 ng/ml). Percentage of Sytox-positive cells among Hoechst 3342 (nuclear stain)-positive cells was plotted.

e. Apoptotic caspase cleavage upon 162 bp dsRNA stimulation in $\triangle \mathrm{G} 3 B P$ s or $\Delta \mathrm{G} 3 \mathrm{BPs} \Delta$ caspase- 8 U2OS cells (left) and in the presence or absence of the caspase- 8 inhibitor (Casp-8i) in U2OS $\triangle$ G3BPs cells (right). Casp-8i is Z-IETD-FMK (50 $\mu \mathrm{M})$.

f. Phosphorylation of RIPK1 in U2OS $\Delta$ G3BPs cells treated with Casp-8i. Cells were pretreated with Z-IETD-FMK $(50 \mu \mathrm{M})$ prior to stimulation with $162 \mathrm{bp}$ dsRNA $(500 \mathrm{ng} / \mathrm{ml})$ and were harvested $24 \mathrm{hr}$ post-dsRNA. The result shows that Z-IETD-FMK blocks cleavage of caspase- 8 in $\triangle \mathrm{G} 3 \mathrm{BPs}$ cells, but instead induces RIPK1-mediated necroptosis. As a control, necroptosis was induced with the combination of Z-IETD-FMK $(50 \mu \mathrm{M})$ and TNF $\alpha(20 \mathrm{ng} / \mathrm{ml})$ as in (a). Necrostatin-1 (nec-1), a known inhibitor of RIPK1, was used to validate the phospho-specific antibody for RIPK1.

g. Colocalization of RIG-I, MAVS and LC3B (red) with G3BP1 (green) in WT U2OS cells in the presence of pan-caspase inhibitor (Q-VD-OPh, $10 \mu \mathrm{M})$. Cells were imaged $24 \mathrm{hr}$ post transfection with $162 \mathrm{bp}$ dsRNA containing 5'ppp (500 $\mathrm{ng} / \mathrm{ml})$.

h. The effect of pan-caspase inhibitor (Q-VD-OPh) on antiviral signaling in A549 cells. Cells (WT vs $\Delta$ G3BPs) were transfected with $162 \mathrm{bp}$ dsRNA $(500 \mathrm{ng} / \mathrm{ml})$ and treated with Q-VD-OPh $(10 \mu \mathrm{M}) 2 \mathrm{hr}$ post-dsRNA. Antiviral signaling was measured by the level of IFN $\beta$ (left) and RANTES (right) mRNAs at 4 or $8 \mathrm{hr}$ post-dsRNA. Note that these time points are earlier than those used for U2OS cells, because A549 cells respond to dsRNA more rapidly than U2OS cells.

Data in (d) and (h) are presented in means $\pm S D$, where $n=6$ and $n=2$, respectively. All data are representative of at least two independent experiments. 
a

b
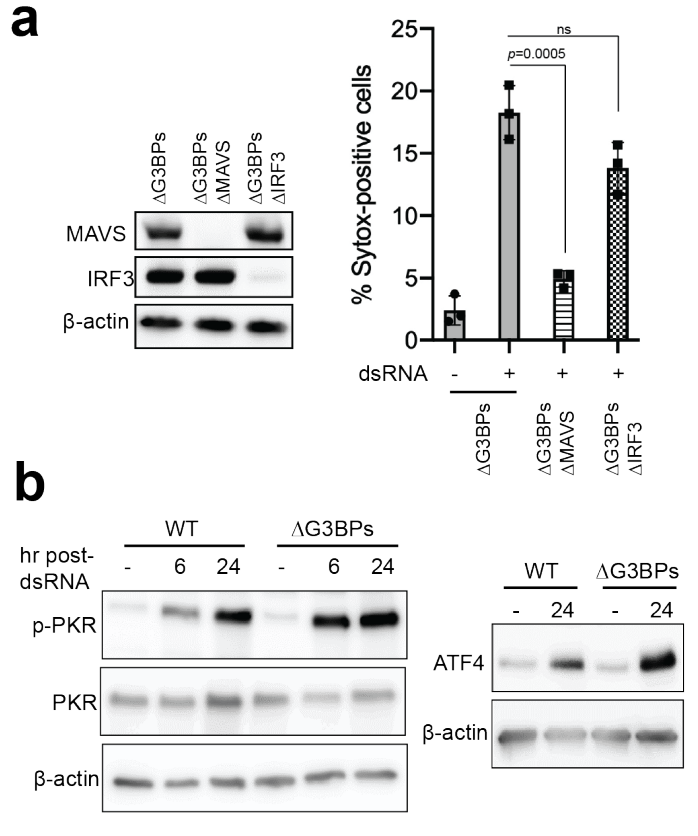

C

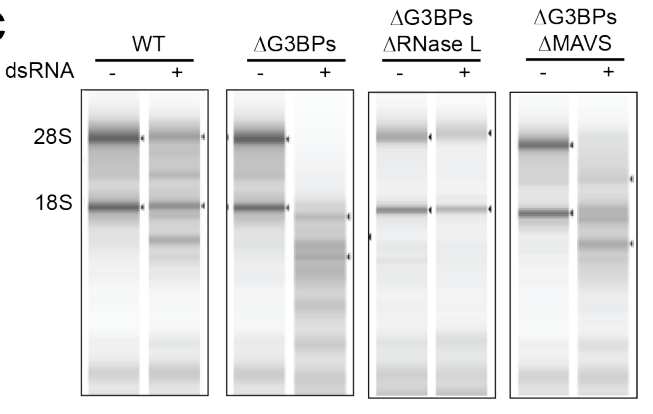

f

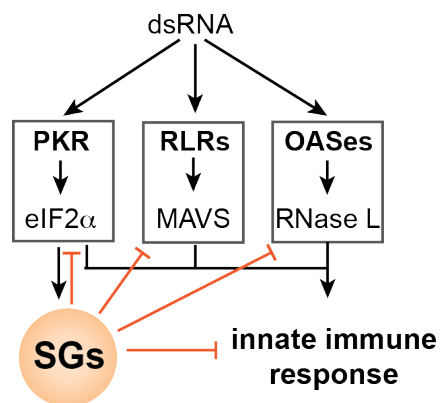

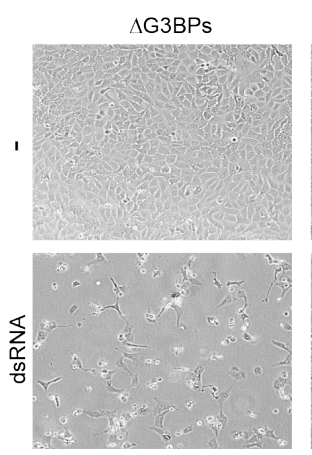

$\triangle \mathrm{G} 3 \mathrm{BP} \triangle \mathrm{MAVS}$
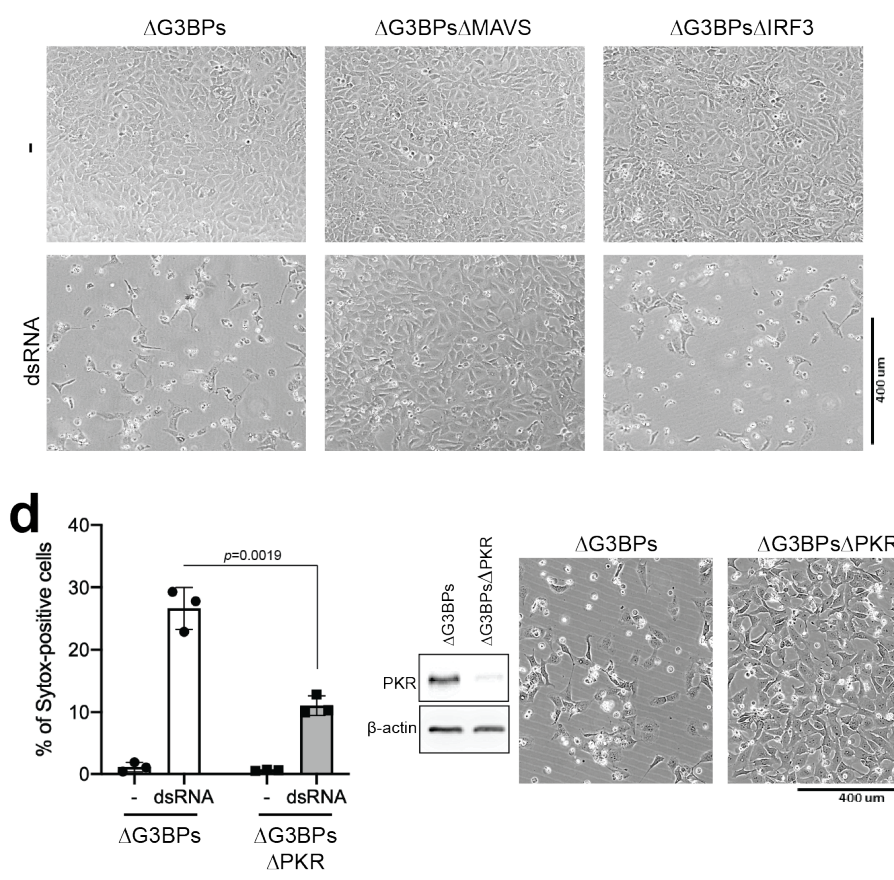

$\triangle \mathrm{G} 3 \mathrm{BP} \triangle \mathrm{PKR}$

e
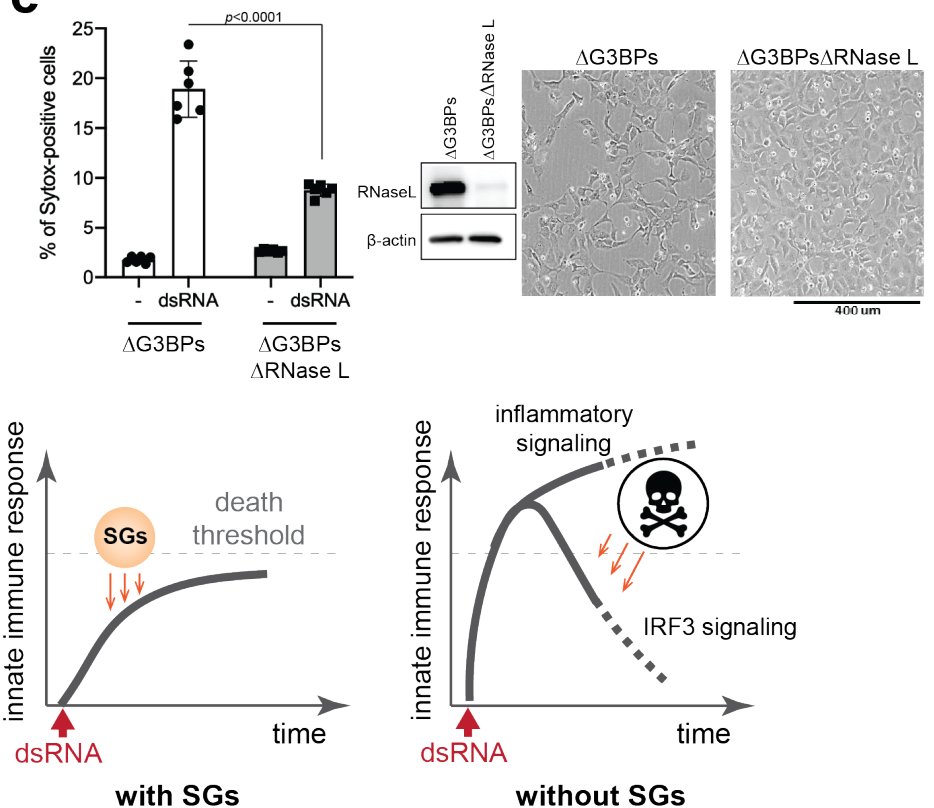

Figure 4. SGs suppress a broad range of innate immune pathways and prevent overstimulation by dsRNA and consequent cell death.

a. Cell death in WT, $\triangle$ G3BPs, $\Delta$ G3BPs $\triangle$ MAVS and $\triangle \mathrm{G} 3 \mathrm{BPs} \Delta \mathrm{IRF} 3 \mathrm{U} 2 \mathrm{OS}$ as measured by Sytox uptake (left) and bright field microscopy (right) at $24 \mathrm{hr}$ post-dsRNA. Cells were stimulated with 162 bp dsRNA as in Figure 1b.

b. PKR activity in WT vs $\triangle$ G3BPs U2OS cells as measured by PKR phosphorylation (left) and ATF4 expression (right) at indicated time post-dsRNA.

c. RNase L activity in WT, $\Delta$ G3BPs, $\Delta$ G3BPss $\Delta$ RNaseL and $\Delta$ G3BPs $\Delta$ MAVS U2OS cells as measured by rRNA degradation. Total RNA was isolated $24 \mathrm{hr}$ post-dsRNA and was analyzed by Agilent TapeStation. 
d. Cell death in $\triangle \mathrm{G} 3 \mathrm{BPs}$ and $\triangle \mathrm{G} 3 \mathrm{BPs} \Delta \mathrm{PKR}$ as measured by Sytox uptake (left) and bright field microscopy (right) at $24 \mathrm{hr}$ post-dsRNA.

e. Cell death in $\triangle \mathrm{G} 3 B$ Ps and $\triangle \mathrm{G} 3 B \mathrm{BP} \Delta \mathrm{RNase} \mathrm{L}$ as measured by Sytox uptake (left) and bright field microscopy (right) at $24 \mathrm{hr}$ post-dsRNA stimulation.

f. Schematic summarizing our findings on SG functions. SGs suppress a broad range of dsRNA-triggered innate immune pathways (including the RLR, PKR and OASes pathways), thereby increasing the temporal window for mounting an appropriate immune response while maintaining its magnitude below the "death" threshold. In the absence of SGs, dsRNA sensing pathways are hyperactivated, leading to an excessive innate immune response and consequent cell death. A subbranch downstream of the RLR pathways (e.g. IRF3) shows a spike followed by a strong suppression, which is due to negative feedback regulation by apoptotic caspases.

Data in (a), (d) and (e) are presented in means \pm SD, where $n=3$ for (a) and (d), and $n=6$ for (e). All data are representative of at least three independent experiments. $p$ values were calculated using the two-tailed unpaired Student's t test (ns, $p>0.05$ ). 
a

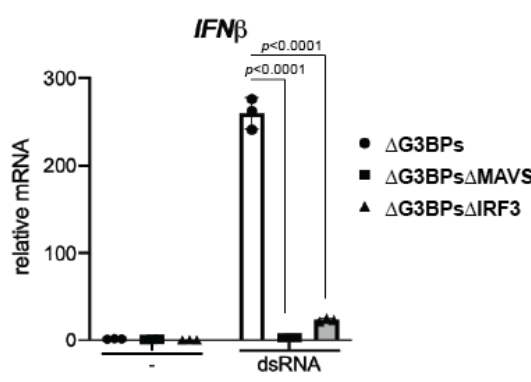

b

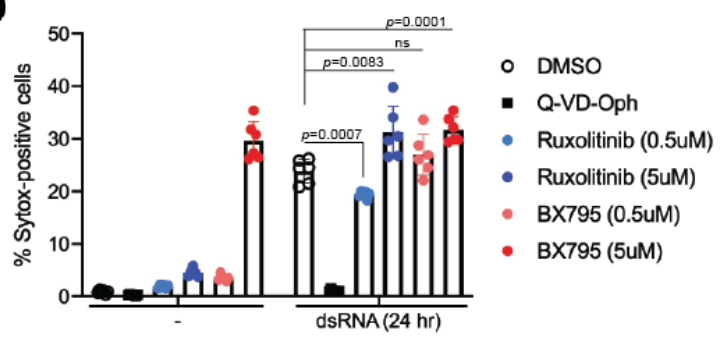

d

\section{C}

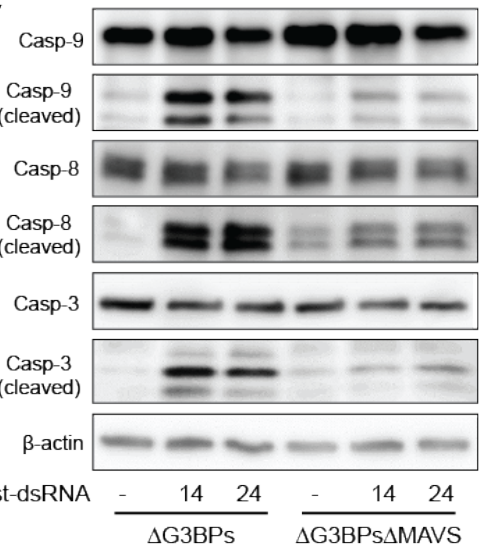

e

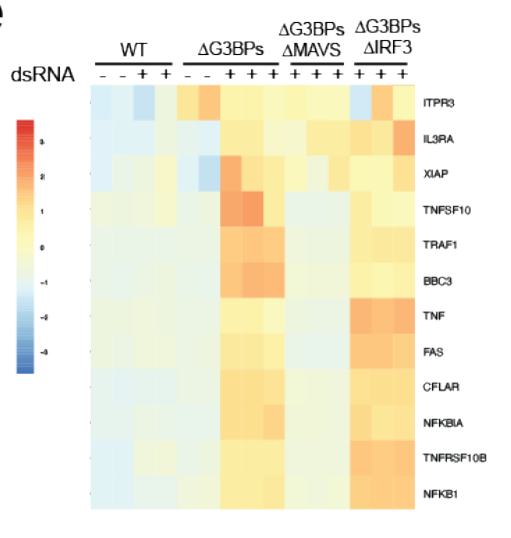

f
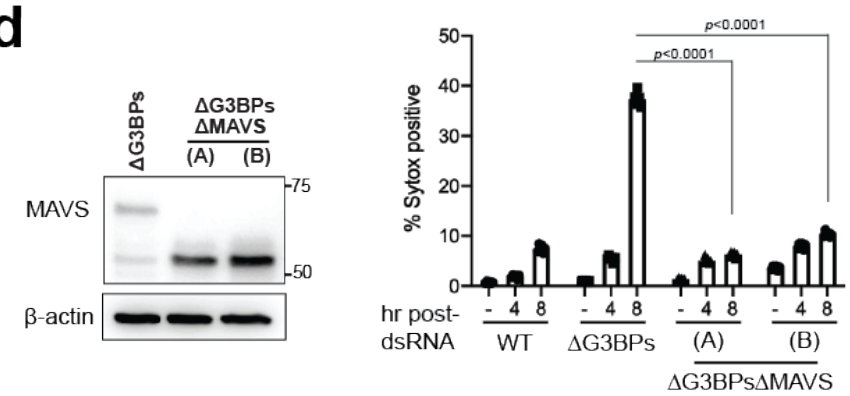

$\triangle \mathrm{G} 3 \mathrm{BPS} A 549$

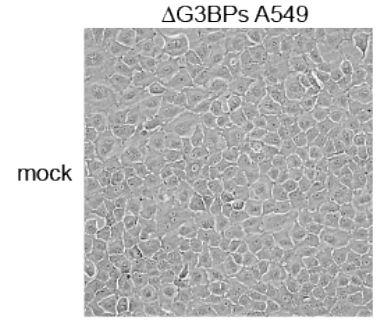

$\triangle G 3 B P s \triangle M A V S(A)$

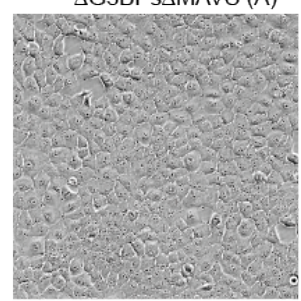

$\triangle \mathrm{G} 3 \mathrm{BPs} \triangle \mathrm{MAVS}(\mathrm{B})$
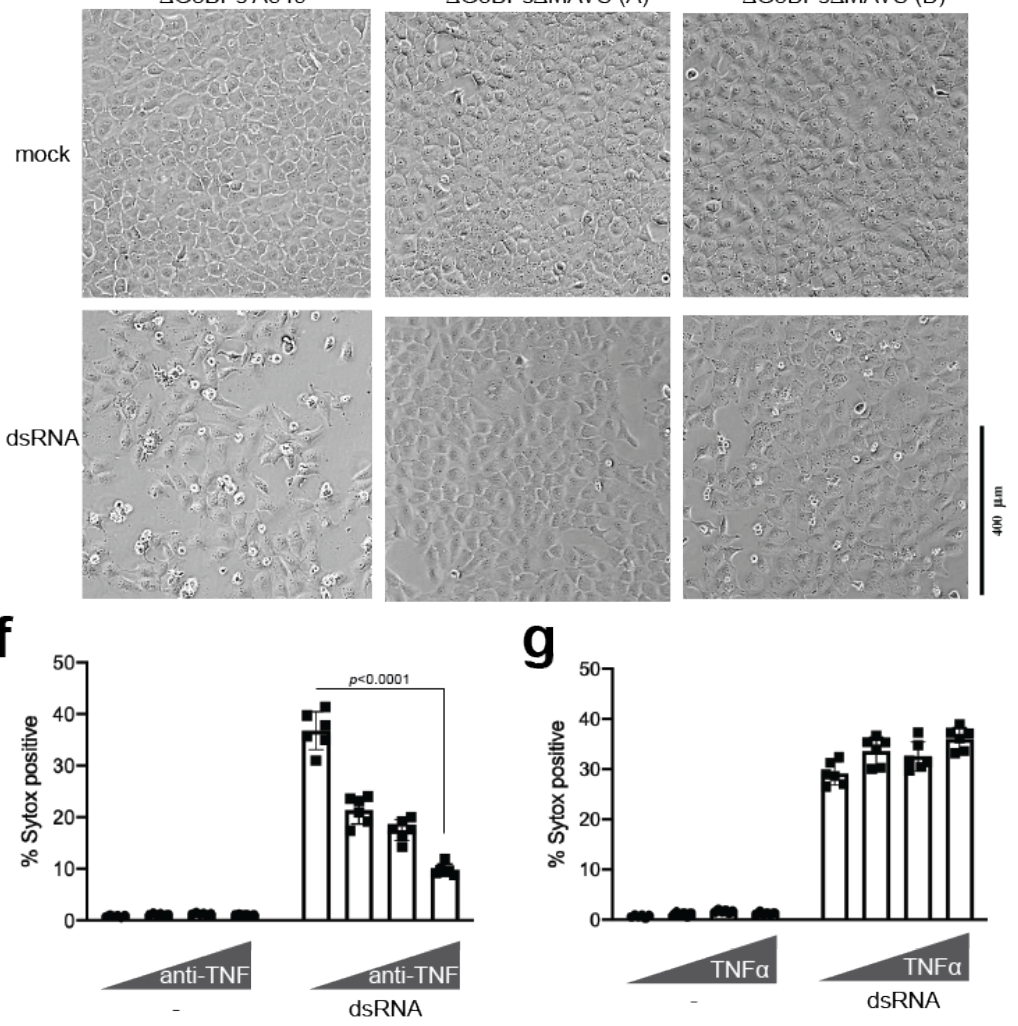

g

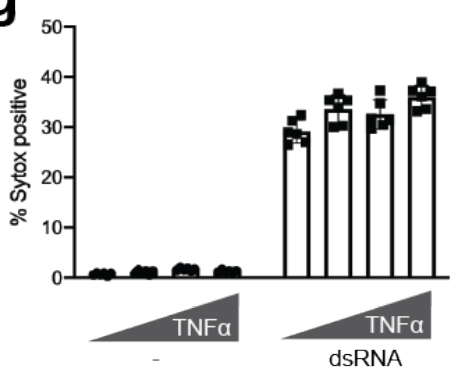

ED Fig 9. Apoptosis in SG-deficient $\triangle$ G3BPs cells is dependent on MAVS.

a. Antiviral signaling in $\Delta \mathrm{G} 3 \mathrm{BPs}, \Delta \mathrm{G} 3 \mathrm{BPs} \Delta \mathrm{MAVS}$ and $\Delta \mathrm{G} 3 \mathrm{BP} \Delta \Delta \mathrm{IRF} 3 \mathrm{U} 2 \mathrm{OS}$ cells in response to dsRNA. Cells were stimulated with dsRNA as in Figure $1 \mathrm{~b}$ and the level of IFN $\beta$ mRNA was measured at $6 \mathrm{hr}$ post-dsRNA.

b. Cell death in U2OS $\triangle$ G3BPs cells in the presence of an inhibitor for TBK1 (BX795) or JAK (Ruxolitinib). Pan-caspase inhibitor Q-VD-Oph $(10 \mu \mathrm{M})$ was used for comparison. 
Cells were pre-treated with the indicated inhibitor 30 min prior to dsRNA transfection $(500 \mathrm{ng} / \mathrm{ml})$. Cell death was measured by Sytox uptake at $24 \mathrm{hr}$ post-dsRNA.

c. Apoptotic caspase cleavage in $\triangle \mathrm{G} 3 B \mathrm{BP}$ and $\triangle \mathrm{G} 3 \mathrm{BP} \Delta \mathrm{MAVS}$ U2OS at $14 \mathrm{or} 24 \mathrm{hr}$ postdsRNA.

d. Cell death in $\triangle$ G3BPs and $\triangle$ G3BPs $\Delta$ MAVS A549 as measured by Sytox uptake (left) and bright field microscopy (right) at $8 \mathrm{hr}$ post-dsRNA. Cells were stimulated with 162 bp dsRNA as in Figure 1b.

e. Heat map of z-scores for differentially expressed genes in apoptosis pathway (KEGG pathway hsa04210) in U2OS WT, $\Delta$ G3BPs, $\Delta \mathrm{G} 3 B P s \Delta$ MAVS and $\Delta$ G3BPs $\Delta$ IRF3 cells at $6 \mathrm{hr}$ post-dsRNA stimulation.

f. Cell death in U2OS $\triangle$ G3BPs cells in response to dsRNA in the presence of anti-TNF $\alpha$. Cells were pre-treated with anti-TNF $\alpha$ antibody $(0.01,0.1$ and $1 \mu \mathrm{g} / \mathrm{ml}) 30 \mathrm{~min}$ prior to transfection with dsRNA $(500 \mathrm{ng} / \mathrm{ml})$. Cell death was measured by Sytox uptake at $24 \mathrm{hr}$ post-dsRNA.

g. Cell death in U2OS $\triangle \mathrm{G} 3 \mathrm{BP}$ s cells in response to an increasing concentration of TNF $\alpha$ $(10,20,50 \mathrm{ng} / \mathrm{ml})$. Cell death was measured by Sytox uptake at $24 \mathrm{hr}$ post-treatment.

Data in (b), (d), (f) and (g) are presented in means \pm SD $(n=6)$. Data in (a) are presented in means $\pm \mathrm{SD}$ with $n=3$. All data are representative of at least three independent experiments. $p$ values were calculated using the two-tailed unpaired Student's t test (ns, $p>0.05$ ). 


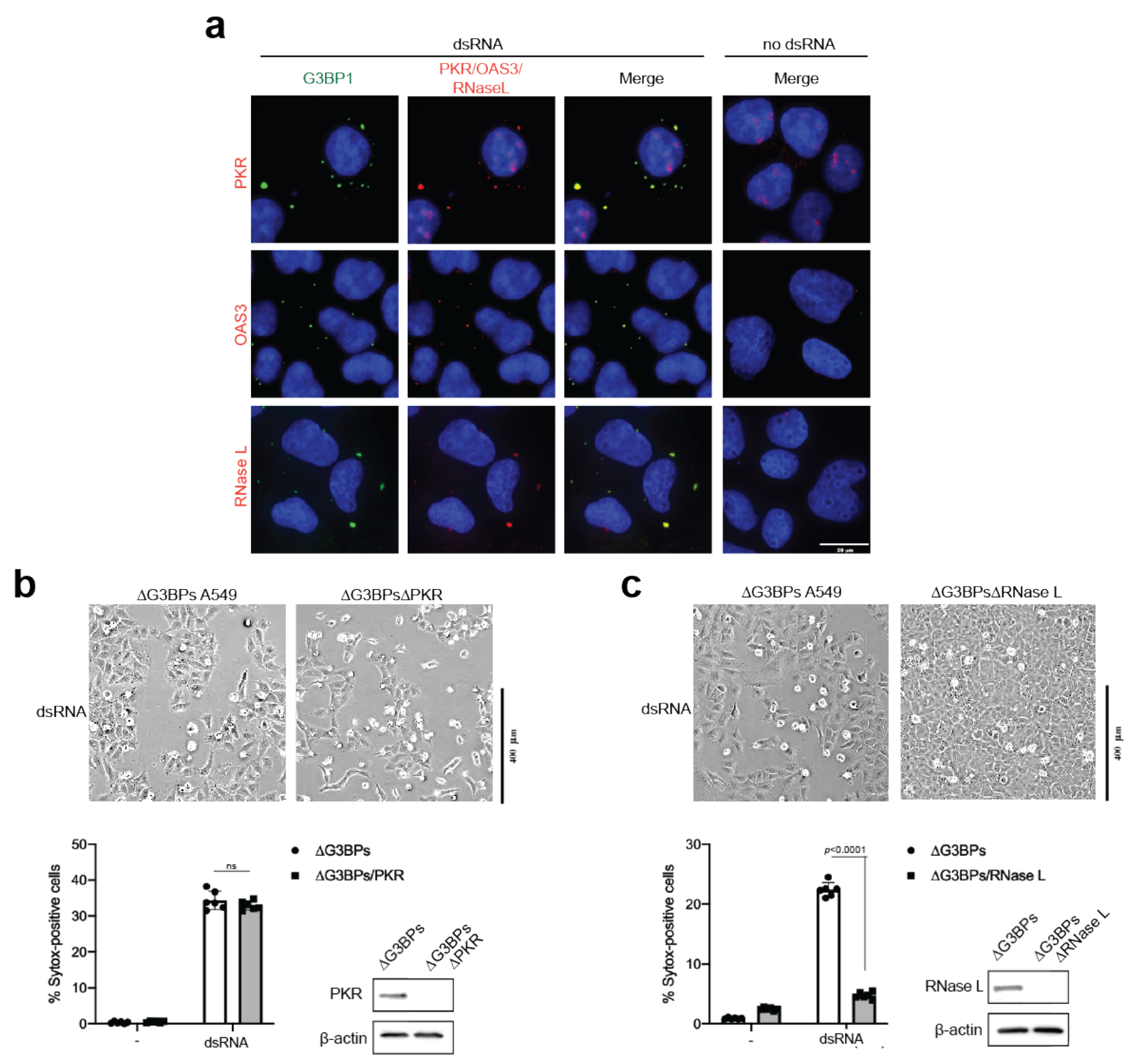

ED Fig 10. SGs recruit PKR, OAS3 and RNase L upon dsRNA stimulation and suppress their activities.

a. Colocalization of PKR, OAS3 and RNase L (red) with G3BP1 (green) in WT U2OS cells by immunofluorescence. Cells were stimulated with dsRNA for $6 \mathrm{hr}$ as in Figure $1 \mathrm{~b}$.

b. Cell death in $\triangle \mathrm{G} 3 \mathrm{BPs}$ and $\triangle \mathrm{G} 3 \mathrm{BPs} \Delta \mathrm{PKR} A 549$ cells in response to dsRNA. The parental $\triangle$ G3BPs is the clone A in Extended Data Fig 7c. Cell death was measured by brightfield microscopy (top) and Sytox uptake (bottom) at $8 \mathrm{hr}$ post-dsRNA.

c. Cell death in $\triangle \mathrm{G} 3 \mathrm{BP}$ s and $\Delta \mathrm{G} 3 \mathrm{BP} \Delta \mathrm{R}$ Nase L A549 cells in response to dsRNA. The parental $\triangle \mathrm{G} 3 \mathrm{BPs}$ is the clone A in Extended Data Fig 7c. Cell death was measured by brightfield (top) and Sytox uptake (bottom) at $8 \mathrm{hr}$ post-dsRNA. 
Data in (b) and (c) are presented in means $\pm \operatorname{SD}(n=6)$. All data are representative of at least two independent experiments. $p$ values were calculated using the two-tailed unpaired Student's test (ns, $p>0.05$ ). 
bioRxiv preprint doi: https://doi.org/10.1101/2021.04.26.441141; this version posted April 27, 2021. The copyright holder for this preprint (which was not certified by peer review) is the author/funder. All rights reserved. No reuse allowed without permission.

\section{Methods and Materials}

\section{Contact for reagent and resource sharing}

Further information and requests for reagents may be directed to and will be fulfilled by the corresponding author Sun Hur (Sun.Hur@crystal.harvard.edu).

\section{Reagents}

For cell treatments the following compounds were used: Bafilomycin A1 (50-100 nM, Sigma Aldrich, Cat\#B1793), SAR405 (1 $\mu \mathrm{M}$, SelleckChem, S7682), Q-VD-Oph (10 $\mu \mathrm{M}$, SelleckChem, S7311), 2'-3'-cGAMP (1-10 $\mu \mathrm{g} / \mathrm{ml}$, Invivogen, tlrl-nacga23), Doxycycline (1 $\mu \mathrm{g} / \mathrm{ml}$, Fisher Scientific, BP26531), Staurosporine (1 $\mu \mathrm{M}$, SelleckChem, S1421), Etoposide (20 $\mu \mathrm{M}$, SelleckChem, S1225), Necrostatin-1 (50 $\mu \mathrm{M}$, SelleckChem, S8037), LPS-B5 (Invivogen, $2 \mu \mathrm{g} / \mathrm{ml}$, tlrl-b5lps), Z-IETD-FMK (50 $\mu \mathrm{M}$, SelleckChem, S7314), human TNF- $\alpha(10-50 \mathrm{ng} / \mathrm{ml}$, Cell Signaling, 8902), Human TNF- $\alpha$ Neutralizing Rabbit mAb (10-1000 ng/ml, Cell Signaling, 7321), Tetraethylthiuram disulfide (Disulfiram 10-25 $\mu \mathrm{M}$, Sigma-Aldrich, 86720),

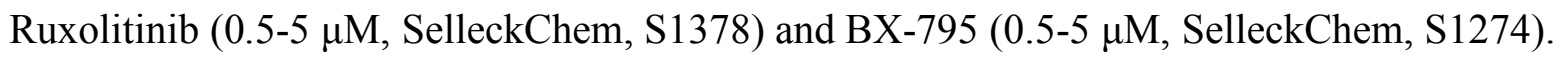

For western blotting (WB) and immunofluorescence (IF), antibodies and their manufacturers were: rabbit $\alpha-G 3 B P 1$ (Cell Signaling, 1:1000 for WB, 1:200 for IF, \#17798), mouse $\alpha$-G3BP1 (Santa Cruz, 1:200 for IF, sc-365338), rabbit $\alpha$-RIG-I (in-house, 1:5000 for WB, 1:400 for IF, Oh et al., 2016) ${ }^{1}$, rabbit $\alpha$-MAVS (Bethyl Laboratories, 1:2000 for WB, 1:200 for IF, A300-782A), mouse $\alpha$-TIAR (Santa Cruz, 1:200 for IF, sc-398372), rabbit $\alpha-$ phospho-IRF3 (Cell Signaling, 1:1000 for WB, \#4947), rabbit $\alpha$-IRF3 (in-house, 1:200 for IF, Oh et al., 2016), rabbit $\alpha$-IRF3 (Cell signaling, 1:1000 for WB, \#4302), rabbit $\alpha$-actin (Cell Signaling, 1:5000 for WB, \#4970), rabbit $\alpha$-LC3B (Cell Signaling, 1:200 for IF, \#2775), mouse $\alpha$-LC3B (Cell Signaling, 1:200 for IF, \#83506), rabbit $\alpha$-G3BP2 (Bethyl Laboratories, 1:200 for IF, A302-040A), rabbit $\alpha$-MDA5 (Cell Signaling, 1:200 for IF, \#5321), mouse $\alpha$-TRAF2 (Santa Cruz, 1:100 for IF, sc-136999), mouse $\alpha$-TRAF6 (Santa Cruz, 1:100 for IF, sc-8409), rabbit $\alpha$-TBK1 (Cell Signaling, 1:200 for IF, \#3054), rabbit $\alpha$-PARP (Cell Signaling, 1:1000 for WB, \#9532), rabbit $\alpha$-Caspase-1 (Cell Signaling, 1:1000 for WB, \#2225), rabbit $\alpha$-Caspase3 (Cell Signaling, 1:1000 for WB, \#9662), rabbit $\alpha$-Caspase 8 (Cell Signaling, 1:1000 for WB, \#4790), rabbit $\alpha$-Caspase 8 (Sigma, 1:1000 for WB, NB100-56116), rabbit $\alpha$-Caspase-9 (Cell Signaling, 1:1000 for WB, \#9502), rabbit $\alpha$-RIP (Cell Signaling, 1:1000 for WB, \#3493), rabbit $\alpha$-phospho-RIP (Cell Signaling, 1:1000 for WB, 65746S), rabbit $\alpha$-ATG7 (Cell Signaling, 1:1000 for WB, \#8558), rabbit $\alpha$-LAMP2 (Thermo Fisher, 1:200 for IF, PA1-655), rabbit $\alpha$ - 
bioRxiv preprint doi: https://doi.org/10.1101/2021.04.26.441141; this version posted April 27, 2021. The copyright holder for this preprint (which was not certified by peer review) is the author/funder. All rights reserved. No reuse allowed without permission.

Cathepsin D (Abcam, 1:200 for IF, ab75852), rabbit $\alpha$-phospho-PKR (Abcam, 1:1000 for WB, ab32036), rabbit- $\alpha$-PKR (Cell Signaling, 1:1000 for WB, 1:200 for IF, \#12297) mouse- $\alpha$ OAS3 (Santa Cruz, 1:100 for IF, sc-398225), rabbit $\alpha$-RNase L (Cell Signaling, 1:1000 for WB, \#2728), mouse $\alpha$-RNase L (Santa Cruz, 1:100 for IF, sc-74405), rabbit $\alpha$-ATF4 (Cell Signaling, 1:1000 for WB, \#11815), $\alpha$-rabbit IgG-HRP (Cell Signaling, 1:10,000 for WB, 7074P2) and $\alpha$-mouse IgG-HRP (GE Healthcare, 1:5000 for WB, \# NA931V).

Double-stranded RNAs (dsRNAs) used in this study were prepared by in vitro T7 transcription as described previously. ${ }^{2}$ The templates for RNA synthesis were generated by PCR amplification. The sequences of the 162 dsRNAs were taken from the first $150 \mathrm{bp}$ of the MDA5 gene flanked by 5'-gggaga and 5'-tctccc. The two complementary strands were cotranscribed, and the duplex was separated from unannealed ssRNAs by $8.5 \%$ acrylamide gel electrophoresis in TBE buffer. RNA was gel-extracted using the Elutrap electroelution kit (Whatman), ethanol precipitated, and stored in $20 \mathrm{mM}$ Hepes, $\mathrm{pH}$ 7.0. Qualities of RNAs were analyzed by TBE polyacrylamide gel electrophoresis. For 3'-FITC labeling of RNA, the 3' end of RNA was oxidized with $0.1 \mathrm{M}$ sodium meta-periodate (Pierce) overnight in $0.1 \mathrm{M} \mathrm{NaOAc}$ $\mathrm{pH}$ 5.4. The reaction was quenched with $250 \mathrm{mM} \mathrm{KCl}$, buffer exchanged using Zeba desalting columns (Thermo Fisher) into 0.1 M NaOAc pH 5.4 and further incubated with Fluorescein-5Thiosemicarbazide (Thermo Fisher) for $6 \mathrm{hr}$ at RT.

Sendai virus (Cantell strain) was purchased from Charles River. Encephalomyocarditis virus (murine) was purchased from ATCC (VR-129B).

\section{Plasmids}

The plentiCRISPRv2 puro was a gift from Brett Stringer (Addgene plasmid \#98290). The plasmids psPAX2 and pMD2.G VSV-G were a kind gift from dr. James DeCaprio, MD, Dana-Farber Cancer institute. To generate the pInducer20-Keima-RIG-I, full length RIG-I containing an N-terminal FLAG tag was cloned into pInducer20 (kindly provided by Dr. Hidde Ploegh, Boston Children's Hospital) using NotI and AscI sites. Next, monomeric Keima was cloned from pHAGE-Keima-LC3-NTAP (kindly provided by Dr. Wade Harper, Harvard Medical School) N-terminal to RIG-I using a single NotI site.

\section{Cell lines}

U2OS, A549, HeLa and HEK293T cells were used for all experiments in this paper. The parental wild-type U2OS, G3BP1 and G3BP2 double knock-out cell lines were kindly 
bioRxiv preprint doi: https://doi.org/10.1101/2021.04.26.441141; this version posted April 27, 2021. The copyright holder for this preprint (which was not certified by peer review) is the author/funder. All rights reserved. No reuse allowed without permission.

provided by Dr. Paul J. Anderson and described elsewhere ${ }^{3}$. The U2OS PKR knock-out cell line was generated by Dr. Shawn B. Lyons and kindly provided by him and by Dr. Paul J. Anderson. Briefly, DNA encoding a guide RNA which targets the 5th exon of PKR were cloned into pCas-Guide (Origene) according to manufacturer's instructions. U2OS cells were cotransfected with pCas-Guide-PKR and pDonor-D09 using Lipofectamine 2000 (Invitrogen). The following day, cells were selected with $1.5 \mathrm{mg} / \mathrm{ml}$ of puromycin for $48 \mathrm{hr}$ to select for transfectants. Single cell clones were isolated by limiting dilution and confirmed by western blotting and genomic sequencing. HEK293T cells were purchased from ATCC (CRL-11268). The parental A549 and A549 RNase L knock-out cells were kindly provided by Dr. Susan Weiss, University of Pennsylvania ${ }^{4}$. The parental Hela cells were kindly provided by Dr. Gracjan Michlewski, University of Edinburgh.

For U2OS cells, for the generation of the ATG7, Caspase 8 (in $\triangle \mathrm{G} 3 \mathrm{BPs}$ ) and PKR (in $\triangle$ G3BPs) knock out cell lines, the ribonucleoprotein complex with gRNA (IDT) and Alt-R $\mathbb{R}$ S.p. Cas9 Nuclease V3 (IDT) was delivered using Lipofectamine 3000 (Thermo Fisher). After $48 \mathrm{hr}$, media was refreshed, and single clones were isolated by limiting dilution and confirmed by western blotting and genomic sequencing. For the generation of the MAVS (both in WT and $\Delta \mathrm{G} 3 \mathrm{BP}$ s backgrounds), RNase L (in $\Delta \mathrm{G} 3 \mathrm{BP}$ ), RIG-I and IRF3 (in $\Delta \mathrm{G} 3 \mathrm{BPs}$ ) knockout cell lines, gRNA was cloned in the pLentiCRISPRv2 vector using the restriction enzyme BsmBI. 293T cells were transfected with the following plasmids at a 3:1:0.7 ratio: (i) pLentiCRISPRv2 with the gRNA, (ii) pMD2.G VSV-G and (iii) psPAX2. U2OS (WT and $\triangle$ G3BPs) were infected with $0.45 \mu \mathrm{M}$ filtered supernatants harvested at $48 \mathrm{hr}$ post-transfection for $48 \mathrm{hr}$, then selected with $1 \mu \mathrm{g} / \mathrm{ml}$ neomycin.

For Hela $\Delta$ G3BPs and A549 $\Delta$ G3BPs, cells were first transduced using a gRNA targeting G3BP1 as described above. After transduction, the ribonucleoprotein complex with gRNA targeting G3BP2 and Alt-R ${ }^{\circledR}$ S.p. Cas9 Nuclease V3 (IDT) was delivered using Lipofectamine 3000, as described above as well. For generation of RNase L, MAVS and PKR knockout in A549 $\Delta$ G3BPs the same gRNA and same approach was used as described for the U2OS cells. A list of all gRNAs can be found in Supplementary Table 1. Single cell clones were isolated by limiting dilution and confirmed by western blotting and genomic sequencing. All cells were maintained at $5.0 \% \mathrm{CO}_{2}$ in Dulbecco's modified Eagle medium (Cellgro) containing 10\% fetal bovine serum and 1\% L-glutamine. Cell lines were routinely tested for mycoplasma contamination. 


\section{RT-qPCR, RNA-seq and rRNA degradation}

For RT-qPCR cells were transfected at 80\% confluency with $500 \mathrm{ng} / \mathrm{ml} 162 \mathrm{bp}$ dsRNA with 5'ppp. Lipofectamine 2000 (Invitrogen) was used for transfection with $2 \mu$ lipofectamine reagent per $\mu \mathrm{g}$ of dsRNA diluted in $50 \mathrm{ul}$ Opti-MEM (Thermo Fisher) per $500 \mathrm{ng}$ of dsRNA. For mock transfection, cells were transfected with only lipofectamine reagent diluted in OptiMEM. At indicated timepoints, total RNAs were extracted using TRIzol reagent (Thermo Fisher) and cDNA was synthesized using High-Capacity cDNA reverse transcription kit (Applied Biosystems) according to the manufacturer's instruction. Real-time PCR was performed using a set of gene-specific primers, a SYBR Green Master Mix (Applied Biosystems), and the StepOne ${ }^{\mathrm{TM}}$ Real-Time PCR Systems (Applied Biosystems). The full list of gene-specific primers can be found in table S2. To determine the effect of Q-VD-Oph on signaling, cells were pre-treated for $1 \mathrm{hr}$ with either DMSO or $10 \mu \mathrm{M} \mathrm{Q}-\mathrm{VD}-\mathrm{Oph}$ prior to dsRNA transfection. For SeV infection, cells were infected with $\mathrm{SeV}$ (100 HA units/ml) with $1 \mathrm{hr}$ of absorption. For EMCV infection, cells were infected with the virus at a MOI $=0.1$ with $1 \mathrm{hr}$ absorption. For cGAMP stimulation, cells were permeabilized with digitonin buffer (50

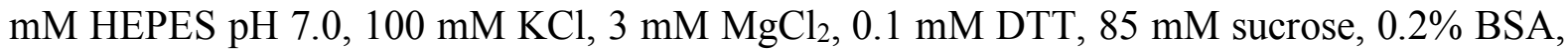
$1 \mathrm{mM}$ ATP, $10 \mu \mathrm{g} / \mathrm{ml}$ digitonin (High Purity, Calbiochem, CAS 11024-24-1)) with 10 or 20 $\mu \mathrm{g} / \mathrm{ml}$ cGAMP for $30 \mathrm{~min}$. After $30 \mathrm{~min}$, complete Dulbecco's modified Eagle medium with $10 \%$ fetal bovine serum was added and total RNA was extracted at $6 \mathrm{hr}$ post-transfection.

For RNA-seq, cells were seeded in 6-wells plate and stimulated with $1 \mu \mathrm{g} 162 \mathrm{bp}$ dsRNA with 5' ppp as described above. At indicated timepoints total RNAs were extracted from indicated cells using TRIzol reagent (Thermo Fisher) and RNA Clean \& Concentrator (Zymo Research). Quality control and mRNA-seq library construction were performed by Novogene Co. Libraries were sequenced on the Illumina NovaSeq 6000 instrument with a paired-end read length of $2 \times 150 \mathrm{bp}$, which resulted in $\sim 20 \mathrm{M}$ reads per sample. The raw sequence files were pre-processed using Trimmomatic v. 0.36 to trim Illumina adaptor sequences and low-quality bases. Trimmed reads were mapped to the human genome (UCSC hg38) using STAR aligner v. 2.5.4a. HTseq-count (v. 0.9.1) was used to count gene reads. Gene-count normalization and differential analysis were performed with DESeq2 ${ }^{5}$. Heatmaps were generated using Pheatmap. Scatter plots were generated using ggplot2. 
bioRxiv preprint doi: https://doi.org/10.1101/2021.04.26.441141; this version posted April 27, 2021. The copyright holder for this preprint (which was not certified by peer review) is the author/funder. All rights reserved. No reuse allowed without permission.

For the RNA degradation analysis, total RNA was isolated from cells and loaded on an RNA pico chip using an Agilent Bioanalyzer.

\section{Immunoblotting}

For immuno-blotting, cells were seeded at $80 \%$ confluency in 6- or 12-well plates and transfected with $500 \mathrm{ng} / \mathrm{ml} 162 \mathrm{bp}$ dsRNA with 5'ppp with lipofectamine 2000 (Invitrogen) as described above. At indicated timepoints, cells were lysed with 1\% SDS lysis buffer (10 mM Tris $\mathrm{pH}$ 7.5, $150 \mathrm{mM} \mathrm{NaCl}, 10 \mathrm{mM}$ DTT, 1\% SDS), then boiled for $10 \mathrm{~min}$. Proteins were resolved on 4-15\% gradient gels (Biorad), transferred to PVDF membranes, and blotted using standard procedures. Membranes were visualized using Amersham ECL reagent (Cytiva) or SuperSignal $^{\mathrm{TM}}$ West Femto Maximum Sensitivity Substrate (Thermo Fisher).

\section{Immunofluorescence microscopy and image analysis}

U2OS, Hela or A549 cells were seeded on coverslips to reach $60-80 \%$ confluency the next day. Cells were stimulated with $500 \mathrm{ng} / \mathrm{ml} 162 \mathrm{bp}$ dsRNA for $6 \mathrm{hr}$ as mentioned previously. At indicated timepoints, cells were fixed with 4\% paraformaldehyde at RT for 10 min, and permeabilized with $0.2 \%$ Triton-X at RT for $10 \mathrm{~min}$. Cells were blocked for $30 \mathrm{~min}$ at RT with $1 \%$ BSA in PBST, and stained using primary antibody for $1 \mathrm{hr}$ at RT. For secondary staining, Alexa Fluor 647® Affinipure Donkey anti-rabbit IgG (Jackson ImmunoResearch) and Alexa Fluor ${ }^{\circledR} 488$ Affinipure Donkey anti-mouse IgG (Jackson ImmunoResearch) were used. Hoechst 3342 (Thermo Fisher) or DAPI (Thermo Fisher) was used to stain the nuclei. Images were obtained using a Zeiss Axio Imager M1 at 40X magnification. For electroporation of dsRNA, 162 bp dsRNA with 5'ppp was electroporated into cells using a Nucleofector ${ }^{\mathrm{TM}} 2 \mathrm{~b}$ (Lonza). $2 \mathrm{~g} / \mathrm{ml}$ of dsRNA was electroporated into cells using the cell line Nucleofector ${ }^{\mathrm{TM}} \mathrm{Kit}$ L (Lonza) by following the manufacturer's instructions using the U2OS program. At $8 \mathrm{hr}$ postelectroporation the cells were fixed as mentioned before. For SeV infection, cells were infected with $\mathrm{SeV}(100 \mathrm{HA} / \mathrm{ml})$ with $1 \mathrm{hr}$ of absorption. For EMCV infection, cells were infected with EMCV (MOI 0.1) with $1 \mathrm{hr}$ of absorption. For bafilomycin A1 and SAR405 treatment, cells were transfected with 162 bp dsRNA and DMSO, bafilomycin A1 $(50 \mathrm{nM})$ or SAR405 $(1 \mu \mathrm{M})$ was added at $2 \mathrm{hr}$ post-transfection. For Q-VD-Oph treatment, cells were pre-treated with DMSO or Q-VD-Oph $(10 \mu \mathrm{M})$ for $1 \mathrm{hr}$ prior to dsRNA stimulation. For detection of dsRNA, 162 bp dsRNA 3'-labeled with Cy3 was transfected using Lipofectamine 2000 as described above. At $6 \mathrm{hr}$ post-transfection cells were fixed and images were obtained using a Nikon TI2 motorized inverted microscope with a 60x oil-immersed lens. All images were processed and 
bioRxiv preprint doi: https://doi.org/10.1101/2021.04.26.441141; this version posted April 27, 2021. The copyright holder for this preprint (which was not certified by peer review) is the author/funder. All rights reserved. No reuse allowed without permission.

analyzed with ImageJ. To highlight SGs, contrast adjustment was based on the mock transfected cells. To determine the Manders Overlap Coefficient, the ImageJ plugin JaCOP was used on 3 separate FOV with at least 40 granules per FOV. In the figure legends, only the Manders overlap coefficient is shown when analyzing the overlap of the SG protein with G3BP1.

For nuclear IRF3 localization, U2OS WT and $\triangle$ G3BPs cells were stimulated with 162 bp dsRNA containing a 5'ppp (100 ng) for 6 or $16 \mathrm{hr}$. Cells were prepared for immunofluorescence and stained with IRF3 (provided by Takashi Fujita) or DAPI. Images were taken randomly across the slide and the presence of IRF3 in the nucleus of each cell was quantified using ImageJ. The pixel intensity of nuclear IRF3 signal in each cell (a.u) were used to plot the data points.

For stress granule size analysis, U2OS WT, U2OS $\Delta \mathrm{PKR}$ and U2OS $\Delta$ ATG7 cells were stimulated with $162 \mathrm{bp}$ dsRNA with 5'ppp for $6 \mathrm{hr}$ as mentioned previously. Cells were fixed and stained for G3BP. Z-stack images $(0.15 \mu \mathrm{M}$ step size) were obtained using a Nikon TI2 motorized inverted microscope. All images were taken with a 60x oil-immersion lens. Stress granule size was determined by using the 3D Object Counter plugin in ImageJ. $100 \mathrm{SG}$ from multiple fields of view (FOV) were picked randomly and analyzed.

\section{Cell death analysis and caspase cleavage assay}

Cell detachment upon stimulation of cells was assessed at the indicated timepoints using the Nikon Eclipse TS2R at 20X magnification. For brightfield images, cells were seeded at $90 \%$ confluency in 12-well plates and transfected with $500 \mathrm{ng}$ per well of $162 \mathrm{bp}$ dsRNA with 5'ppp. At indicated timepoints, brightfield images were acquired from 3 different wells for each sample in duplicate. For the brightfield images of figure S8A and S8B, cells were stimulated with different cell death stimuli. U2OS $\triangle$ G3BPs cells were treated with 162 bp dsRNA (500 ng/ml), etoposide $(20 \mu \mathrm{M})$ or Z-IETD-FMK $(50 \mu \mathrm{M})$ plus TNF $\alpha(20 \mathrm{ng} / \mathrm{ml})$ for $24 \mathrm{hr}$. For LPS induced pyroptosis, cells were transfected with $2 \mu \mathrm{g}$ LPS-B5 for $24 \mathrm{hr}$ using the same transfection protocol as used for dsRNA. At $24 \mathrm{hr}$ post-treatment, the brightfield images were obtained using the Nikon Eclipse TS2R at 40X magnification.

For quantification of cell death, U2OS, Hela and A549 cells were seeded in 12-well plates and transfected with 500 ng per well with 162 bp dsRNA with 5'ppp unless otherwise indicated. At the indicated timepoints, cells were incubated with Sytox Green Nucleic Acid stain (Thermo Fisher) (2 $\mu \mathrm{M}$ final) and Hoechst 33342 (Thermo Fisher, 3,000-fold dilution) 
bioRxiv preprint doi: https://doi.org/10.1101/2021.04.26.441141; this version posted April 27, 2021. The copyright holder for this preprint (which was not certified by peer review) is the author/funder. All rights reserved. No reuse allowed without permission.

for $30 \mathrm{~min}$. Sytox Green signal was measured with the Nikon Eclipse TS2R at 20X magnification using a 470 ex filter set. The percentage of dead cells was calculated as the number of Sytox positive cells divided by the total number of Hoechst positive cells using ImageJ. To determine the effect of different drugs on dsRNA-induced cell death, cells were pre-treated with DMSO, disulfiram (10 or $25 \mu \mathrm{M})$, Q-VD-Oph $(10 \mu \mathrm{M})$, Human TNF- $\alpha$ Neutralizing Rabbit mAb (10, 100, $1000 \mathrm{ng} / \mathrm{ml})$, Ruxolitinib $(0.5$ or $5 \mu \mathrm{M})$ or BX-795 $(0.5$ or $5 \mu \mathrm{M}$ ) for $1 \mathrm{hr}$ prior to dsRNA transfection. For figure S7B, U2OS WT or $\Delta \mathrm{G} 3 \mathrm{BPs}$ cells were treated with DMSO, staurosporine $(1 \mu \mathrm{M})$ or etoposide $(50 \mu \mathrm{M})$ for $24 \mathrm{hr}$ prior to performing the Sytox assay. For figure S9F cells were either mock treated with PBS or with human TNF$\alpha(10,20$ or $50 \mathrm{ng} / \mathrm{ml})$ for $24 \mathrm{hr}$ prior to performing the Sytox assay.

Live/Dead ${ }^{\mathrm{TM}}$ cell imaging kit (Thermo Fisher) was used to quantify cell death in U2OS WT and U2OS $\Delta \mathrm{G} 3 \mathrm{BP} 1 / 2$ at the indicated timepoints. The manufacturer's instructions were followed for this analysis. To quantify caspase $3 / 7$ cleavage, cells were stimulated with dsRNA as previously mentioned and caspase $3 / 7$ activity was analyzed using the CellEvent ${ }^{\mathrm{TM}}$ Caspase 3-7 Green detection reagent (Invitrogen). Similar to Sytox, the cells were stained with the Green detection reagent $(1: 30,000)$ and Hoechst 33342 for 30 min. Sytox Green signal was measured with the Nikon Eclipse TS2R at 40X magnification using a 470 ex filter set. The percentage of cells with active Caspase 3/7 was calculated as the number of green cells divided by the total number of Hoechst positive cells using ImageJ. For figure 3C, the caspase 3/7 activity was measured using a Biotek M1 Synergy microplate reader using the manufacturer's instructions. All experiments were performed at $n=3$.

\section{Flow cytometry}

0.1 million A549 cells transduced with Keima-RIG-I were seeded in 12-well plates and cultured with $1 \mu \mathrm{g} / \mathrm{ml}$ of doxycycline for $24 \mathrm{hr}$ to induce Keima-RIG-I expression. Cells were transfected with 162 bp dsRNA with 5'ppp using Lipofectamine 2000 (Invitrogen). $100 \mathrm{nM}$ bafilomycin A1 or DMSO was added to cells at $4 \mathrm{hr}$ post-transfection. Cells were harvested 16 hr post-transfection and resuspended in FACS buffer (1xPBS, 0.5\% BSA, $0.05 \% \mathrm{NaN}_{3}$, final pH 7.4). Keima expression data were acquired on FACSCanto (BD Biosciences) and analyzed with FlowJo software.

\section{IRF3 dimerization assay}


bioRxiv preprint doi: https://doi.org/10.1101/2021.04.26.441141; this version posted April 27, 2021. The copyright holder for this preprint (which was not certified by peer review) is the author/funder. All rights reserved. No reuse allowed without permission.

This assay was adapted from the method described previously ${ }^{6}$. Briefly, U2OS cells

(mock or 112 bp dsRNA-transfected) were homogenized in hypotonic buffer (10 mM Tris $\mathrm{pH}$ 7.5, $10 \mathrm{mM} \mathrm{KCl}, 0.5 \mathrm{mM}$ EGTA, $1.5 \mathrm{mM} \mathrm{MgCl}_{2}, 1 \mathrm{mM}$ sodium orthovanadate, $1 \mathrm{X}$ mammalian Protease Arrest (GBiosciences, 786-108)) and centrifuged at 1,000 g for 5 min to pellet the nuclei. The supernatant (S1), containing the cytosolic and the mitochondrial fractions, was further centrifuged at 5,000 g for $15 \mathrm{~min}$ to pellet the crude mitochondrial fraction (P5). The P5 fraction was further washed once with isotonic buffer (hypotonic +0.25 M D-Mannitol). The cytosolic fraction for the experiment was extracted from wild type untransfected U2OS cells using the same procedure as above except that the final spin was done at 18,000 $\mathrm{g}$ for $15 \mathrm{~min}$ and the supernatant S18 containing the cytosolic fraction was recovered. Subsequently, $35 \mu \mathrm{g}$ of each P5 pellet was resuspended in $25 \mu \mathrm{S} 18(3 \mathrm{mg} / \mathrm{ml})$ and used for IRF3 dimerization assay and Western blot analysis. ${ }^{35} \mathrm{~S}-\mathrm{IRF} 3$ was prepared by in vitro translation using TnT T7 Coupled Reticulocyte Lysate System (Promega, L4610) according to manufacturer's instructions. The IRF3 dimerization was carried out by adding $16 \mu \mathrm{l}(\mathrm{P} 5+\mathrm{S} 18) \mathrm{mix}$ to $2 \mu \mathrm{l}^{35} \mathrm{~S}-\mathrm{IRF} 3$ in $(20 \mathrm{mM}$ HEPES $\mathrm{pH} 7.4,4 \mathrm{mM} \mathrm{MgCl} 2$ and $2 \mathrm{mM}$ ATP) in a total reaction volume of $20 \mu \mathrm{l}$. The reaction was incubated at $30^{\circ} \mathrm{C}$ for $1 \mathrm{~h}$ followed by centrifugation at $18,000 \mathrm{~g}$ for $5 \mathrm{~min}$ and the supernatant was subjected to native PAGE analysis. IRF3 dimerization was visualized by autoradiography and phosphorimaging on Amersham Typhoon 5 Biomolecular Imager (GE Healthcare). The image was quantified using ImageQuant.

\section{Quantification and Statistical analysis}

Average values and standard deviations were calculated using Microsoft excel and SPSS (IBM). The values for $n$ represent biological replicates for cellular experiments or individual samples for biochemical assays. For each figure, individual replicate values were plotted together with the average values. The number of replicates is also indicated in the figure legends. Unless otherwise mentioned, all assays were performed in at least 3 independent experiments. $p$ values were calculated using the two-tailed unpaired Student's t test and are shown in the graphs.

\section{References}

1. Oh, S.-W. et al. Leader-Containing Uncapped Viral Transcript Activates RIG-I in 
bioRxiv preprint doi: https://doi.org/10.1101/2021.04.26.441141; this version posted April 27, 2021. The copyright holder for this preprint (which was not certified by peer review) is the author/funder. All rights reserved. No reuse allowed without permission.

Antiviral Stress Granules. PLOS Pathog. 12, e1005444 (2016).

2. Peisley, A. et al. Kinetic mechanism for viral dsRNA length discrimination by MDA5 filaments. Proc. Natl. Acad. Sci. 109, E3340-E3349 (2012).

3. Kedersha, N. et al. G3BP-Caprin1-USP10 complexes mediate stress granule condensation and associate with 40S subunits. J. Cell Biol. 212, (2016).

4. Li, Y. et al. Ribonuclease L mediates the cell-lethal phenotype of double-stranded RNA editing enzyme ADAR1 deficiency in a human cell line. Elife 6, (2017).

5. Love, M. I., Huber, W. \& Anders, S. Moderated estimation of fold change and dispersion for RNA-seq data with DESeq2. Genome Biol. 15, 550 (2014).

6. Ahmad, S. et al. Breaching Self-Tolerance to Alu Duplex RNA Underlies MDA5Mediated Inflammation. Cell 172, 797-810.e13 (2018). 
bioRxiv preprint doi: https://doi.org/10.1101/2021.04.26.441141; this version posted April 27, 2021. The copyright holder for this preprint (which was not certified by peer review) is the author/funder. All rights reserved. No reuse allowed without permission.

Table S1. List of gRNAs used in this study

\begin{tabular}{|l|l|}
\hline Name & Sequence \\
\hline G3BP1 gRNA1 & GGAGAAGCCTAGTCCCCTGC \\
\hline G3BP1 gRNA2 & CTAGTCCCCTGCTGGTCGGG \\
\hline G3BP2 gRNA1 & GAGTGATGGAGTAGTTGTCC \\
\hline G3BP2 gRNA2 & GAAATCTACTACTCCTCCTC \\
\hline RIG-I gRNA & TCGTGCTCGGTGGTCATGC \\
\hline MAVS gRNA & CACCGCCCGGGCCGCCGCTGAA \\
\hline PKR gRNA ${ }^{1}$ & ATTATGAACAGTGTGCATCG \\
\hline PKR gRNA $1^{2}$ & TAATACATACCGTCAGAAGC \\
\hline PKR gRNA 2 & \\
\hline IRF3 gRNA 1 & TTATCCATGGGGAATTACAT \\
\hline IRF3 gRNA 2 & CACCGGACACCTCTCCGGACACCAA \\
\hline Caspase 8 gRNA & AAACTTGGTGTCCGGAGAGGTGTCC \\
\hline RNase L gRNA & \\
\hline
\end{tabular}

1. Used for generating U2OS $\triangle \mathrm{PKR}$

2. Used for generating U2OS $\Delta \mathrm{G} 3 \mathrm{BP} \Delta \mathrm{PKKR}$ and $\mathrm{A} 549 \Delta \mathrm{G} 3 \mathrm{BP} \Delta \mathrm{P} K \mathrm{KR}$ 
bioRxiv preprint doi: https://doi.org/10.1101/2021.04.26.441141; this version posted April 27, 2021. The copyright holder for this preprint (which was not certified by peer review) is the author/funder. All rights reserved. No reuse allowed without permission.

Table S2. Gene-specific primer sequences used for RT-qPCR

\begin{tabular}{|l|l|}
\hline Name & Sequence \\
\hline Human IFN- $\beta$ fwd & AAACTCATGAGCAGTCTGCA \\
\hline Human IFN- $\beta$ rev & AGGAGATCTTCAGTTTCGGAGG \\
\hline Human RANTES fwd & TACACCAGTGGCAAGTGCTC \\
\hline Human RANTES rev & TGTACTCCCGAACCCATTTC \\
\hline Human IL-6 fwd & GGAGACTTGCCTGGTGAAAA \\
\hline Human IL-6 rev & GTCAGGGGTGGTTATTGCAT \\
\hline Human ACTIN- $\beta$ fwd & GCACAGAGCCTCGCCTT \\
\hline Human ACTIN- $\beta$ rev & GTTGTCGACAGCG \\
\hline
\end{tabular}

